\title{
Single and combined use of Cannabis sativa L. and carbon-rich materials for the removal of pesticides and endocrine-disrupting chemicals from water and soil
}

\author{
Elisabetta Loffredo ${ }^{1}$ (D) $\cdot$ Giuseppe Picca $^{1} \cdot$ Marco Parlavecchia $^{1}$
}

Received: 8 June 2020 / Accepted: 31 August 2020 / Published online: 14 September 2020

(C) The Author(s) 2020

\begin{abstract}
Hemp (Cannabis sativa L.) seedlings were used to remove from water the fungicide metalaxyl-M and the endocrine disruptor (EDC) bisphenol A (BPA) at concentrations ranging from 2 to $100 \mu \mathrm{gL}^{-1}$. In 7 days of exposure, despite the phytotoxicity of each compound that reduced elongation and biomass, the seedlings were able to remove between 67 and $94 \%$ of metalaxyl-M and between 86 and $95 \%$ of BPA. The amounts of metalaxyl-M and BPA extracted from plant dry biomass were in the range of 106$3861 \mu \mathrm{g} \mathrm{g}^{-1}$ and $16-101 \mu \mathrm{g} \mathrm{g}^{-1}$, respectively, and resulted positively correlated to both the dose of compound added $(P \leq 0.01)$ and the amount removed by the plants $(P \leq 0.01)$. Plant uptake and transformation were the main mechanisms involved in the removal of the compounds. In another set of experiments, hemp was used to remove a mixture of two pesticides, metalaxyl-M and metribuzin, and three EDCs, BPA, 17ß-estradiol (E2), and 4-tert-octylphenol (OP), at concentrations of 10, 10, 10, 10, and $1 \mu \mathrm{g} \mathrm{g}^{-1}$, respectively, from soil column not added and added with $2.5 \%$ (w/w) of a green compost (CM) or a wood biochar (BC). In 25 days, plants did not alter considerably the distribution of the compounds along the soil profile and were capable of removing, on average, 12, 11, 10, 9, and 14\% of metalaxyl-M, metribuzin, BPA, E2, and OP, respectively. During growth, hemp transformed the compounds and accumulated part of them (except $\mathrm{OP}$ ) mainly in the shoots. CM and, especially, BC significantly protected the plants from the toxicity of the compounds and enhanced the retention of the latter in soil, contrasting leaching. Thus, the single or synergistic use of hemp and amendments deserves attention being a very low-cost and eco-sustainable strategy to remediate water and soil.
\end{abstract}

Keywords Hemp · Phytoremediation · Biochar · Compost - Endocrine disruptor · Water Decontamination · Plant uptake · Organic contaminant

\section{Introduction}

A primary concern of the last years is the increasing presence in the environment of the so-called emerging pollutants (EPs). EPs are synthetic or naturally occurring chemicals that are not commonly monitored in the environment, but that have the potential to enter into it causing known or suspected adverse ecological and human health effects (Geissena et al. 2015).

Responsible Editor: Tito Roberto Cadaval Jr

Elisabetta Loffredo

elisabetta.loffredo@uniba.it

1 Dipartimento di Scienze del Suolo, della Pianta e degli Alimenti, Università degli Studi di Bari Aldo Moro, Via Amendola 165/A, 70126 Bari, Italy
Pesticides, pharmaceuticals, wood preservatives, industrial product and by-products, and dyes are examples of EPs.

A major risk related to these compounds is their high leaching potential, especially for those with low hydrophobicity like some pesticides, thus contaminating groundwater (Arias-Estévez et al. 2008). Metalaxyl-M (methyl $N$-(2,6dimethylphenyl)- $N$-(methoxyacetyl)-D-alaninate)) is the biologically active $\mathrm{R}$-enantiomer of the racemic compound metalaxyl. It is one of the most used fungicide worldwide and is highly persistent, mobile, and leachy in soil (Fernandes et al. 2003). Metribuzin (4-amino-6-tert-butyl-3methylsulfanyl-1,2,4-triazin-5-one) is a selective triazinone herbicide. Because of the high water solubility, it has been included by the United States Environmental Protection Agency into the group of pesticides that have the greatest potential for leaching into groundwater (USEPA 2003).

Among EPs, the endocrine-disrupting chemicals (EDCs) have drawn increasingly extensive attention. These compounds 
are currently ubiquitous in the environment, food, and consumer products and can have severe impact on the endocrine functions of animals, especially aquatic, and humans (DiamantiKandarakis et al. 2009). EDCs may enter surface water, groundwater, and soil through agricultural practices and the application, discharge, and disposal of urban and industrial effluents, sludges, and other wastes. The environmental fate of some endocrine disruptors has been extensively investigated (Baronti et al. 2000; Ying et al. 2002; Campbell et al. 2006).

The xenoestrogen bisphenol A $(2,2-(4,4$ dihydroxydiphenyl) propane, BPA) is one of the chemicals produced in the highest quantities worldwide, with almost 3 million tons produced each year (Vandenberg et al. 2009). BPA is the building block of epoxy resins and polycarbonates and is adopted as stabilizer for polyvinyl chloride. The $17 \beta$ estradiol (17 $\beta$-estra-1,3,5(10)-triene-3,17-diol, E2) is the major endogenous estrogen in humans, and it is present in several hormonal therapy products. The 4-tert-octylphenol (OP) originates by microbial breakdown from the surfactants octylphenol polyethoxylates. This molecule possesses estrogenic activity and is highly recalcitrant to biodegradation (Ying et al. 2002).

The coexistence in cultivated soil of different classes of contaminants, such as pesticides and EDCs, is very likely to occur due to the current agricultural practices that makes extensive use of waste biomass and wastewaters which are rarely thoroughly decontaminated and plant-protective chemicals.

The necessity to provide sustainable solutions to water and soil pollution has led to develop alternative, cost-effective, and eco-friendly technologies for remediating water and soil from contaminants (Morillo and Villaverde 2017; Wu and Wu 2019). Among the numerous remediation methodologies explored and tested in recent years, bio-based technologies seem to be an interesting economical alternative (Gerhardt et al. 2009). Phytoremediation is a process that exploits plant physiological processes, such as transpiration, root exudation, absorption, translocation, and metabolization, and rhizosphere microorganisms to remove mineral and organic pollutants from water, soil, sludge and sediments, both in situ and ex situ. There are various phytoremediation strategies whose choice depends on the type of pollutants and their concentrations, the matrix, and the plant species adopted (McCutcheon and Schnoor 2003; Gerhardt et al. 2009). Phytoextraction or phytoaccumulation consists in absorbing pollutants by the root system and eventually translocate them to the aerial organs, ensuring the permanent decontamination of the site. This technique has been extensively applied to remove metals but also pesticides (Gasco et al. 2019; Tarla et al. 2020). Rhizofiltration is typical not only of aquatic plant species which uptake pollutants from aquatic environments but also of terrestrial plants, such as sunflower or hemp, that have an extended root system and large root surface area (Gerhardt et al. 2009). Phytostabilization or phytoimmobilization relies on the ability of plants to decrease the mobility or bioavailability of pollutants, avoiding their leaching and possible entrance into groundwater or food chain. However, the latter mechanism that concern especially heavy metals does not allow the elimination of pollutants from the contaminated matrix. A relevant role for organic pollutants has played by phytodegradation or phytotransformation. This process regards the capacity of some plants to degrade or transform partially or completely organic contaminants by means of their enzymes. Rhizodegradation concerns an indirect action of plants which produce root exudates containing an easily degradable $\mathrm{C}$-source that stimulate the degradative metabolism of microorganisms in the rhizosphere, acting also on recalcitrant pollutants.

An added value of phytoremediation is that plants give a relevant contribution to soil fertility both directly, through root expansion and exudation, and indirectly promoting the growth and activity of microorganisms (Paz-Ferreiro et al. 2014).

Hemp (Cannabis sativa $\mathrm{L}$.) is an annual herb used in many types of non-food industries. Its high biomass, deep-root and short life cycle, and ease of adaptation to different climatic conditions make it very suitable for phytoremediation. Moreover, hemp has a very high capacity to absorb and accumulate organic and inorganic pollutants (Linger et al. 2002).

Despite its great potential, phytoremediation could have some application limits, especially in heavily contaminated areas, due to the phytotoxicity of pollutants, often present in combination, that could seriously compromise plants survival and growth (McCutcheon and Schnoor 2003). Trying to overcome this problem, increasing attention has been given to the so-called assisted or enhanced phytoremediation that exploits the synergistic combination of plants and C-rich materials (Paz-Ferreiro et al. 2014; Lu et al. 2015; Chirakkara and Reddy 2015; Gasco et al. 2019). This combined strategy has been applied to depollute soil from heavy metals (PazFerreiro et al. 2014; Lu et al. 2015; Gasco et al. 2019) or mixtures of organic and inorganic contaminants (Chirakkara and Reddy 2015).

The addition to the soil of C-rich materials during the phytoremediation could slow down the decontamination process because of the high sorption efficiency of these materials that may attenuate the availability of contaminants to soilresident degrading microorganisms. However, there are some aspects that make this double approach worthy to be explored. One aspect concerns the plant-protective activity of these materials, including a pathogen-suppressive activity, that sustains plant mass production and is very important when plants have to face stressful situations in heavily polluted soils, especially in their early growth stage (Gasco et al. 2019). The precarious conditions of remediating plants make them much more fragile, compromising plant survival and consequently the success of phytoremediation. Furthermore, plant candidates for phytoremediation, like hemp, have excellent capacity to 
uptake pollutants with the water flow and are supposed to be able to effectively compete with the amendments for the retention of contaminants (McCutcheon and Schnoor 2003; Gasco et al. 2019).

The importance of these aspects is the rationale for choosing C-rich materials, including compost (CM) and biochar (BC) to sustain plant remediation. Green CM produced from the wastes of the maintenance of public and private greenery, residues of crops or wood processing, has a remarkable ability to reduce the mobility of organic contaminants in soil (MarínBenito et al. 2018). BC is the stable carbonaceous by-product obtained from thermochemical conversion, at temperatures ranging from 200 to $800{ }^{\circ} \mathrm{C}$, of biomass in limited oxygen conditions (pyrolysis) to produce bio-oil and syngas (IBI 2015). BC, originally designed for carbon sequestration and soil amendment, has proven to be a very efficient low-cost adsorbent of organic and inorganic contaminants and has been increasingly used for soil and water remediation (Zhang et al. 2013; Loffredo and Taskin 2017; Gasco et al. 2019; Parlavecchia et al. 2019; Zheng et al. 2020).

The objectives of this work were to evaluate (i) the potential of hemp to remove metalaxyl-M and BPA from water during germination and early growth and (ii) the effectiveness of hemp, a green CM and a wood BC, individually or in combination, to remediate a soil multi-contaminated with two pesticides and three EDCs and to influence the leaching of these compounds.

\section{Materials and methods}

\section{Chemicals, plant, soil, and materials}

Metalaxyl-M and metribuzin, both at a purity $\geq 98.0 \%$, bisphenol A (BPA) at 99\% purity, 17ß-estradiol (E2) at 99.9\% purity, and 4-tert-octylphenol (OP) at 99.5\% purity were provided by Sigma-Aldrich S.r.l., Milano, Italy. Chemical properties of the compounds are shown in Table 1. All other chemicals of extra pure grade were obtained from commercial sources and used without further purification.

Hemp (Cannabis sativa L.) seeds, cultivar Kompolti, were provided by Emporio Canapuglia S.a.s., Conversano, Italy.

The loamy soil used was sampled at $0-20 \mathrm{~cm}$ depth at an experimental station located in Southern Italy $\left(41^{\circ} 1^{\prime} \mathrm{N}, 16^{\circ}\right.$ $54^{\prime \prime} \mathrm{E}$ ). The soil was air-dried, thoroughly mixed, and 2.0-mm sieved. Some soil properties were determined according to conventional methods. Moisture was determined by heating the soil at $105{ }^{\circ} \mathrm{C}$ overnight. The $\mathrm{pH}$ was measured suspending the soil in distilled water $\left(\operatorname{soil} / \mathrm{H}_{2} \mathrm{O}, 1: 2.5, \mathrm{w} / \mathrm{v}\right)$. Electrical conductivity (EC) was measured by a conductivity meter (soil/ $\left.\mathrm{H}_{2} \mathrm{O}, 1: 2, \mathrm{w} / \mathrm{v}\right)$. Soil organic matter $(\mathrm{SOM})$ was determined by the loss on ignition method (Zhang and
Wang 2014). Total calcium carbonate was determined by the gas-volumetric method using a Dietrich-Fruhling calcimeter. Moisture, $\mathrm{pH}, \mathrm{EC}, \mathrm{SOM}$, and total carbonates of soil were, respectively, $5.0 \% 7.8,0.23 \mathrm{dS} \mathrm{m}^{-1}, 51.3 \mathrm{~g} \mathrm{~kg}^{-1}$, and $20.9 \mathrm{~g} \mathrm{~kg}^{-1}$.

The CM sample was obtained from the composting process of wastes from public and private greenery and residues of crops and wood processing. CM was produced by Tecnogarden Service S.r.l., Vimercate, Italy, and provided by the Italian Composting and Biogas Association (CIC). Moisture, $\mathrm{pH}, \mathrm{EC}$, organic $\mathrm{C}$, and $\mathrm{C} / \mathrm{N}$ ratio of $\mathrm{CM}$ were, respectively, 24\%, 7.8, $1.23 \mathrm{dS} \mathrm{m}^{-1}, 270 \mathrm{~g} \mathrm{~kg}^{-1}$, and 15 (data provided by the producer). The $\mathrm{BC}$ sample was obtained from vineyard pruning residues through a process of microgasification or slow pyrolysis with a thermal maximum of $550{ }^{\circ} \mathrm{C}$ and a duration of the process of $3 \mathrm{~h}$, followed by dry cooling. BC was supplied by Blucomb S.r.l., Udine, Italy. Total organic $\mathrm{C}$, moisture, $\mathrm{pH}, \mathrm{EC}$, and ash of $\mathrm{BC}$ were, respectively, $755 \mathrm{~g} \mathrm{~kg}^{-1}, 4.5 \%, 9.9,2.23 \mathrm{dS} \mathrm{m}^{-1}$, and $9.9 \%$ (Taskin et al. 2019).

\section{Removal of the compounds from water}

Sets of 10 seeds of hemp were placed on filter paper in Petri dishes (9-cm diameter) and supplied with $3 \mathrm{~mL}$ of water (control) or $3 \mathrm{~mL}$ of aqueous solutions of metalaxyl-M or BPA at concentrations of 2, 10, 20, 50, and $100 \mu \mathrm{g} \mathrm{mL}^{-1}$. Samples with contaminant solution only (no seeds) were also prepared to evaluate a possible degradation of the compounds during the experimental time. Seed germination and early growth were achieved in a Phytotron growth chamber at 21 $\pm 1{ }^{\circ} \mathrm{C}$ in the dark for 7 days. Then, seedlings were collected and the germination percentage, root and shoot lengths, and fresh and dry weights were measured. The residual amounts of the chemical in the germination medium was measured using high performance liquid chromatography (HPLC) technique ("HPLC analytical procedure" section).

BPA and metalaxyl-M were extracted from the plants according to the procedure described in Ferrara et al. (2006). Briefly, $0.1 \mathrm{~g}$ of dry mass was added with $10 \mathrm{~mL}$ of pure methanol and kept under mechanical shaking for $4 \mathrm{~h}$. The suspension was then centrifuged for $10 \mathrm{~min}$ at $10,000 \mathrm{~g}$ and an aliquot of $5 \mathrm{~mL}$ of the supernatant solution was evaporated to dryness at a temperature of $40{ }^{\circ} \mathrm{C}$ using a rotatory evaporator. The residue was dissolved in a volume of $2 \mathrm{~mL}$ of acetonitrile/water mixture $(70 / 30, \mathrm{v} / \mathrm{v})$, filtered through $0.45-\mu \mathrm{m}$ Millipore ${ }^{\mathrm{TM}}$ filters and analyzed by HPLC ("HPLC analytical procedure" section).

All experiments were replicated six times and all data obtained were statistically analyzed by one-way analysis of variance (ANOVA) at the 95\%, 99\%, and 99.9\% confidence levels. The means were statistically compared using the least significant difference (LSD) test. 
Table 1 Some properties of the compounds

\begin{tabular}{|c|c|c|c|c|}
\hline Compound & Chemical structure & $\begin{array}{c}\text { Molecular } \\
\text { weight }\left(\mathrm{g} \mathrm{mol}^{-1}\right)\end{array}$ & $\begin{array}{l}\text { Water solubility } \\
\left(\mathrm{mg} \mathrm{L}^{-1} \text { at } 25^{\circ} \mathrm{C}\right)\end{array}$ & $\log \mathrm{K}_{\mathrm{ow}}$ \\
\hline Metalaxyl-M & & 279.33 & 8400 & 1.65 \\
\hline Metribuzin & & 214.29 & 1200 & 1.70 \\
\hline BPA & & 228.29 & 300 & 3.32 \\
\hline E2 & & 272.38 & 3.9 & 4.01 \\
\hline $\mathrm{OP}$ & & 206.32 & 3.1 & 5.50 \\
\hline
\end{tabular}

Data from PubChem open chemistry database at the National Institutes of Health (NIH) (n.d.)

\section{Removal of the compounds from soil column}

A series of columns (30-cm height and 7-cm diameter) were prepared overlapping plexiglass cylinders. The columns were closed at the base with wire mesh and glass wool. Then, $950 \mathrm{~g}$ of air-dried soil was poured in the column filling up to a height of $25 \mathrm{~cm}$. In some columns, $9.5 \mathrm{~g}$ of the $0-10 \mathrm{~cm}$ soil layer was replaced with $9.5 \mathrm{~g}$ of $\mathrm{CM}$ or $\mathrm{BC}(2.5 \% \mathrm{w} / \mathrm{w}$ in the $0-10$ $\mathrm{cm}$ layer). All soil columns were watered up to $60 \%$ of the field capacity. After $2 \mathrm{~h}$, a mixture of $2 \mathrm{mg}$ of metalaxyl-M, $2 \mathrm{mg}$ of metribuzin, $2 \mathrm{mg}$ of BPA, $2 \mathrm{mg}$ of E2, and $0.2 \mathrm{mg}$ of OP was incorporated in the upper soil layer $(\sim 5 \mathrm{~cm})$, achiev-

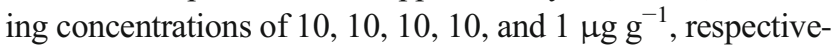
ly. After $2 \mathrm{~h}$, six hemp seeds per column were sowed in half of the columns prepared. The treatments obtained were as follows: soil, soil $+\mathrm{CM}$, soil $+\mathrm{BC}$, soil + plants, soil $+\mathrm{CM}+$ plants, soil $+\mathrm{BC}+$ plants, and uncontaminated soil + plants (control). Then, a volume of $14 \mathrm{~mL}$ of distilled water was added to each column (with and without seeds). All treatments and the control were triplicated. During the 25-day experimental period, a volume of $14 \mathrm{~mL}$ of water per day (total volume of $350 \mathrm{~mL}$ ) was added to each soil column. The experiments were performed in a Phytotron growth chamber at a temperature of $25^{\circ} \mathrm{C}$, relative humidity of $70 \%$, and a photoperiod of $14 \mathrm{~h}$ (Fig. 2). All biometric data of plants were statistically analyzed by ANOVA at the $95 \%, 99 \%$, and 99.9\% confidence levels. The means were statistically compared using the LSD test.

At the end of experiments, plants were collected, roots were rinsed with distilled water, and root and shoot lengths as well as fresh and dry weights (at $70{ }^{\circ} \mathrm{C}$ for $16 \mathrm{~h}$ ) of plants were measured. The extraction of the compounds from plants 
was done according to the procedure of Ferrara et al. (2006), briefly described in the "Removal of the compounds from water" section. Samples were finally analyzed by HPLC ("HPLC analytical procedure" section).

The soil columns were sectioned, and the soil of the various sections $(0-5,5-10,10-15$, and $15-25 \mathrm{~cm})$ was separately mixed. An aliquot of $20 \mathrm{~g}$ of soil sampled from each section was added with $50 \mathrm{~mL}$ of methanol and mechanically shaken for $16 \mathrm{~h}$. Then, the suspension was filtered and an aliquot of 20 $\mathrm{mL}$ was centrifuged at $10,000 \mathrm{~g}$ for $10 \mathrm{~min}$. Supernatants were finally analyzed using HPLC ("HPLC analytical procedure" section). The percentages of recovery from soil of metalaxyl$\mathrm{M}$, metribuzin, BPA, E2, and OP at concentrations of 10, 10, 10,10 , and $1 \mu \mathrm{g} \mathrm{g}^{-1}$ were, respectively, $93.75 \pm 2.70,92.57 \pm$ $1.77,92.43 \pm 0.80,89.18 \pm 2.67$, and $91.82 \pm 2.08(n=4)$. The residual amount of each compound in the whole soil column was calculated as the sum of the amounts extracted in the various sections. The percentages of the compounds disappeared after 25 days in the soil column were calculated as the difference between the initial amounts and those extracted at the end. These data were statistically analyzed by the twoway ANOVA at the $95 \%$ confidence level and the means compared using the LSD test.

\section{HPLC analytical procedure}

The HPLC apparatus consisted of a Spectra System ${ }^{\mathrm{TM}}$ pump (Thermo Electron Corporation, San Josè, CA, USA) equipped with a Rheodyne 7125 injection valve fitted with a $20-\mu \mathrm{L}$ loop and connected to a Supelcosil ${ }^{\mathrm{TM}} \mathrm{LC}-18$ column $(250 \mathrm{~mm} \times$ $4.6 \mathrm{~mm} \times 5 \mu \mathrm{m}$ ). Using a mixture of acetonitrile/water at a ratio of $70 / 30(\mathrm{v} / \mathrm{v})$ as mobile phase and a flow rate of $1 \mathrm{~mL}$ $\min ^{-1}$, the retention time of metalaxyl-M, metribuzin, BPA, E2, and OP were 4.8, 3.8, 7.0, 6.0, and $15.0 \mathrm{~min}$, respectively.

Metalaxyl-M and metribuzin were quantified using a Spectra System UV6000LPTM diode array detector (Thermo Electron Corporation, San Josè, CA, USA) at wavelengths of 220 and $294 \mathrm{~nm}$, respectively. BPA, E2, and OP were quantified using a Spectra SystemFL3000 (Thermo Electron Corporation, San Josè, CA, USA) fluorescence detector operating at wavelengths of $230-\mathrm{nm}$ excitation and $310-\mathrm{nm}$ emission.

The external standard method was adopted to quantify the compounds. Blank samples were prepared for soil and plants in quadruplicate. The matrix effect was investigated by comparing the standards in the appropriate solvent with matrixmatched standards at $1 \mu \mathrm{g} \mathrm{mL}{ }^{-1}$. Results showed that there were not interfering peaks from the matrix and that the retention times of the compounds did not change. All analytes were eluted as separate symmetric peaks. Very good linearities were obtained for all compounds in the ranges 0.05 to $5 \mu \mathrm{g}$ $\mathrm{mL}^{-1}$ and 2 to $100 \mu \mathrm{g} \mathrm{mL}^{-1}$ with $r$ values always higher than 0.999. The limit of detection (LOD), calculated considering a signal to noise ratio $(\mathrm{S} / \mathrm{N})$ of 3 compared with the background noise of the blank, for metalaxyl-M, metribuzin, BPA, E2, and OP were $0.01,0.01,0.01,0.003$, and $0.003 \mathrm{mg} \mathrm{L}^{-1}$, respectively. The limit of quantification (LOQ) were $0.03,0.04$, $0.02,0.01$, and $0.01 \mathrm{mg} \mathrm{L}^{-1}$ for metalaxyl-M, metribuzin, $\mathrm{BPA}, \mathrm{E} 2$, and $\mathrm{OP}$, respectively, with $\mathrm{S} / \mathrm{N}=10$.

\section{Results and discussion}

\section{Removal of the compounds from water}

Both BPA and, especially, metalaxyl-M caused some phytotoxic effects on seedlings, reducing shoot and root elongation and fresh and dry biomass (Fig. 1). However, BPA did not affect germination at any concentration and even significantly stimulated root and shoot elongation at a dose of $10 \mu \mathrm{g} \mathrm{mL}^{-1}$ (Fig. 1). On average for the doses applied, metalaxyl-M reduced dry mass of hemp by about $66 \%$ (excluding the dose of $100 \mu \mathrm{g} \mathrm{mL}^{-1}$ that completely inhibited germination) and BPA by about $43 \%$ (Fig. 1). Teixeira et al. (2011) reported toxic effects on Solanum nigrum L. and biomass decrease starting from metalaxyl concentration of $12.5 \mu \mathrm{g} \mathrm{mL}^{-1}$. BPA addition at concentrations of 10 and $50 \mu \mathrm{g} \mathrm{mL} \mathrm{m}^{-1}$ generally did not inhibit germination and early growth of broad bean, tomato, durum wheat, and lettuce but reduced their dry weights from 10 to $67 \%$ at the lower dose and from 17 to $88 \%$ at the higher dose (Ferrara et al. 2006).

Residual amounts of each compound measured in the medium at the end of experiments are shown in Fig. 2. In the absence of plants, at any concentration, no significant decrease of metalaxyl-M and BPA was obtained, denoting that abiotic degradation had a negligible role (Fig. 2). BPA stability in water for several days was reported in previous studies (Imai et al. 2007; Loffredo et al. 2010). Differently, a significant reduction of each compound at each dose was found in the medium with seedlings. Therefore, despite the young plants were stressed by exposure to the chemicals, they were capable of removing considerable amounts of each compound, especially BPA (Fig. 2). Significant positive correlations were calculated between the initial doses of metalaxyl-M (excluding $100 \mu \mathrm{g} \mathrm{mL}^{-1}$ ) and BPA and the corresponding amounts removed by the seedlings $(P=0.006$ for metalaxyl$\mathrm{M}$ and $P=0.003$ for BPA). Residual BPA in the medium with plants was lower than $5 \%$ at initial concentrations in the range $2-50 \mu \mathrm{g} \mathrm{mL}^{-1}$ and equal to $14 \%$ at the highest concentration (Fig. 2). Imai et al. (2007) found that BPA was rapidly absorbed and metabolized by Portulaca oleracea. Seedlings of various herbaceous species, exposed for 5-7 days to 4.6 and $46 \mu \mathrm{g} \mathrm{mL}^{-1} \mathrm{BPA}$ concentrations, were capable of removing, respectively, from 25 to $98 \%$ and from 30 to $91 \%$ of the contaminant (Loffredo et al. 2010). We can suppose that the removal of these contaminants was primarily due to seedling 


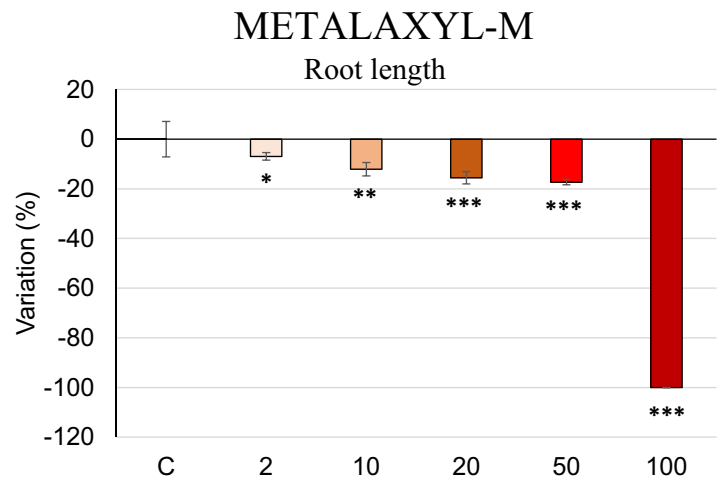

BPA

Root length
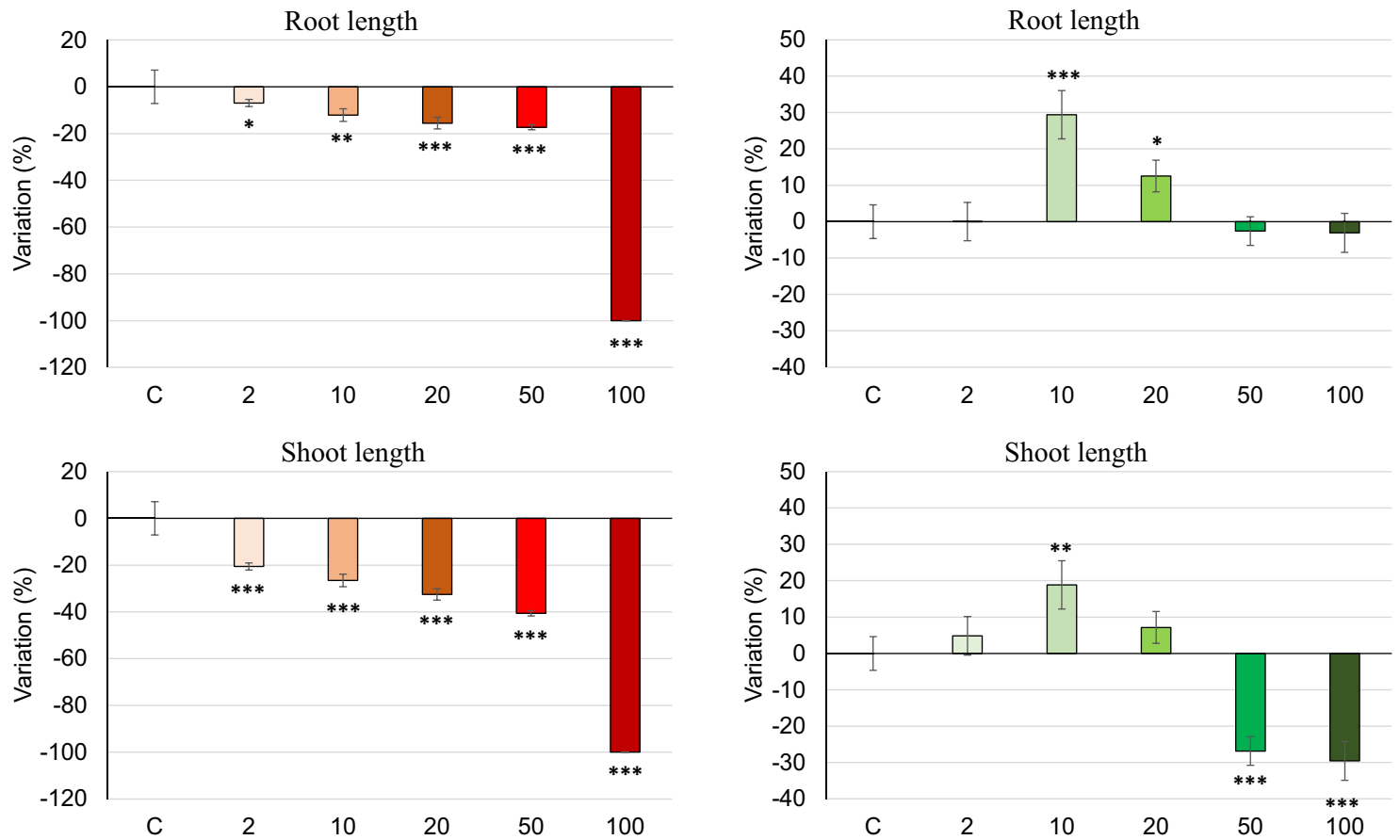

Germination percentage
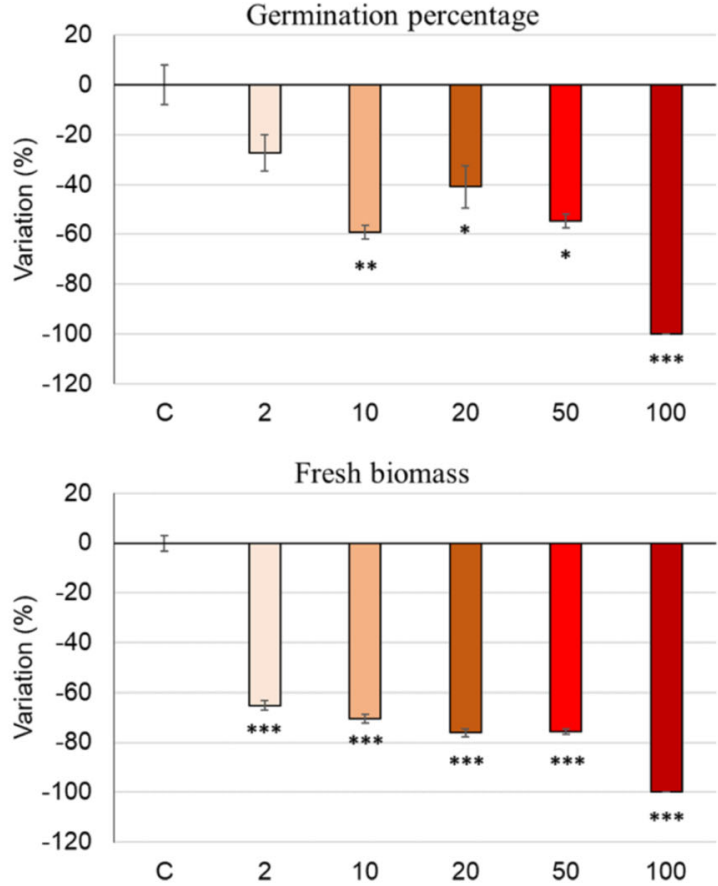

Dry biomass

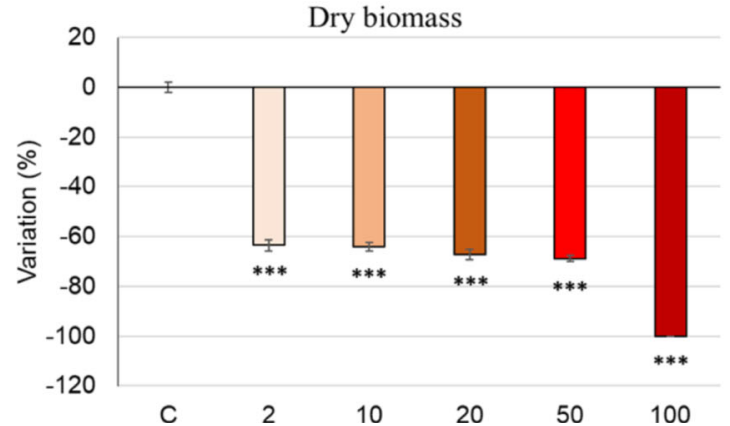

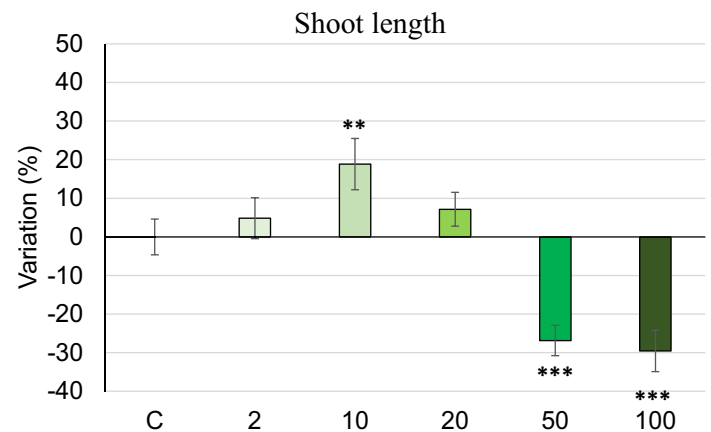

Germination percentage
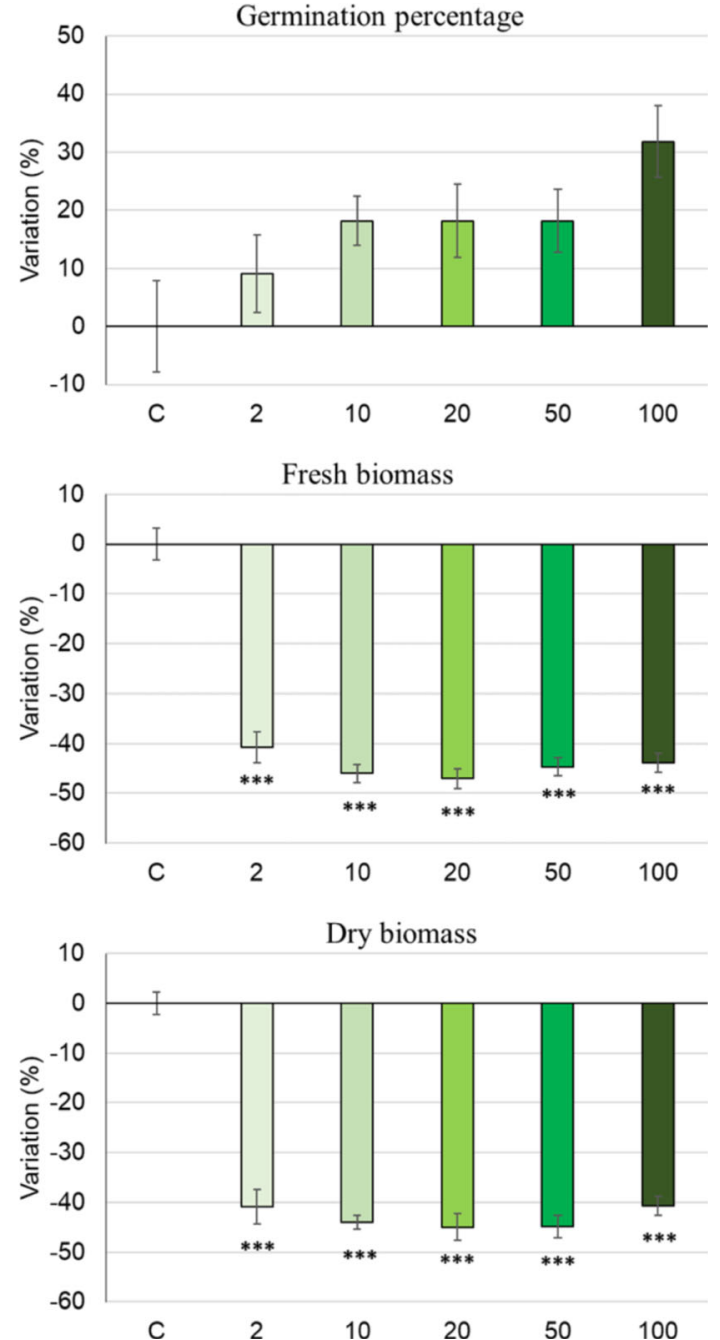
Fig. 1 Effects of the dose $\left(\mu \mathrm{g} \mathrm{mL}^{-1}\right)$ of metalaxyl-M and BPA on biometric parameters of 7-day grown hemp seedlings. $* P \leq 0.05$, $* * P \leq 0.01$, $* * * P \leq 0.001$ according to the least significant difference (LSD) test. The vertical line on each bar indicates the standard error $(n=6)$

absorption and metabolization and also to a possible plantpromoted microbial degradation in the non-axenic medium. Anyway, this aspect was not investigated in this work. Schmidt and Schuphan (2002), studying BPA metabolism in plant cell culture, demonstrated the rapid uptake of this compound by cells.

The amount of compound accumulated in the seedlings exposed for 7 days to various concentrations of metalaxyl-M and BPA, individually, are shown in Table 2. Depending on the initial dose, from 106 to $3861 \mathrm{\mu g} \mathrm{g}^{-1}$ of metalaxyl-M and from 16 to $101 \mu \mathrm{g} \mathrm{g}^{-1}$ of BPA were extracted from dry biomass of seedlings (Table 2). For each compound, the quantity extracted from the seedlings was positively correlated with the initial concentration $(P \leq 0.01)$ and the amount removed by the seedlings $(P \leq 0.01)$ (Fig. 3$)$. Exposing the seedlings to concentrations ranging from 2 to $50 \mu \mathrm{g} \mathrm{mL}^{-1}$, the quantities of metalaxyl-M and BPA accumulated in the tissues were, on average, $20.6 \pm 1.3 \%$ and $3.6 \pm 1.3 \%$, respectively, of the removed amount. Considering similar amounts of compound removed by the seedlings, i.e., $4635 \mu \mathrm{g} \mathrm{g}^{-1}$ of metalaxyl-M

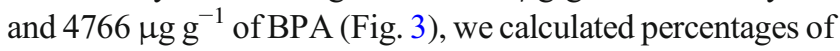
accumulation in plants of 17.8 and $1.3 \%$, respectively. Therefore, these results, along with those concerning hemp growth, indicated that, in the same range of concentrations, metalaxyl-M was absorbed much more than BPA, thus producing strong toxicity on seedlings (also lethal) that compromised seriously also its biotransformation. The different response of hemp to the two compounds is reasonably linked to their hydrophobicity, suggesting, in principle, particular
Table 2 Amount of metalaxyl-M and BPA extracted from hemp seedlings after 7-day growth

\begin{tabular}{ll}
\hline Treatment & Product extracted $\left(\mu \mathrm{g} \mathrm{g}^{-1}\right.$ of dry plant mass $)$ \\
\hline $\begin{array}{l}\text { Metalaxyl-M } \\
2 \mathrm{mg} \mathrm{L}\end{array}$ & $105.56 \pm 1.79^{\mathrm{a}} \mathrm{a}^{\mathrm{b}}$ \\
$10 \mathrm{mg} \mathrm{L}^{-1}$ & $825.73 \pm 58.25 \mathrm{~b}$ \\
$20 \mathrm{mg} \mathrm{L}^{-1}$ & $1477.37 \pm 155.72 \mathrm{c}$ \\
$50 \mathrm{mg} \mathrm{L}^{-1}$ & $3860.81 \pm 156.28 \mathrm{~d}$ \\
$\mathrm{BPA}$ & \\
$2 \mathrm{mg} \mathrm{L}$ & $16.28 \pm 1.47 \mathrm{a}$ \\
$10 \mathrm{mg} \mathrm{L}^{-1}$ & $29.00 \pm 3.23 \mathrm{~b}$ \\
$20 \mathrm{mg} \mathrm{L}^{-1}$ & $47.05 \pm 6.51 \mathrm{c}$ \\
$50 \mathrm{mg} \mathrm{L}^{-1}$ & $63.66 \pm 6.33 \mathrm{~d}$ \\
$100 \mathrm{mg} \mathrm{L}^{-1}$ & $100.74 \pm 7.48 \mathrm{e}$ \\
\hline
\end{tabular}

${ }^{\text {a }}$ Standard error of the mean $(n=6)$

${ }^{\mathrm{b}}$ Data were statistically treated by the LSD test at $P \leq 0.05$

attention in the use of hemp for the decontamination of matrices heavily polluted by highly soluble compounds. However, this aspect needs to be explored in adult plants.

Few information is present in the literature on the absorption and accumulation of these contaminants by plants. Gong et al. (2020) ascribed the rapid absorption and translocation of metalaxyl-M in plants to both its hydrophilicity and the small molecular size that allowed an easy passage through cell membrane and Casparian strip. Perennial ryegrass and radish, exposed for 16 days to 4.6 and $46 \mu \mathrm{g}$ $\mathrm{mL}^{-1}$ BPA concentrations, accumulated in dry plant mass, respectively, 0.8 and $2.7 \%$ of initial BPA at the lower dose and 0.2 and $0.4 \%$ at the higher dose, indicating an efficient metabolization of this compound (Loffredo et al. 2010).
Fig. 2 Effects of the dose of metalaxyl-M (a) and BPA (b) on the residual compound in the medium in the absence and presence of hemp. Data are expressed as percentages of the initial amount of compound added. The vertical line on each bar indicates the standard error $(n=6)$
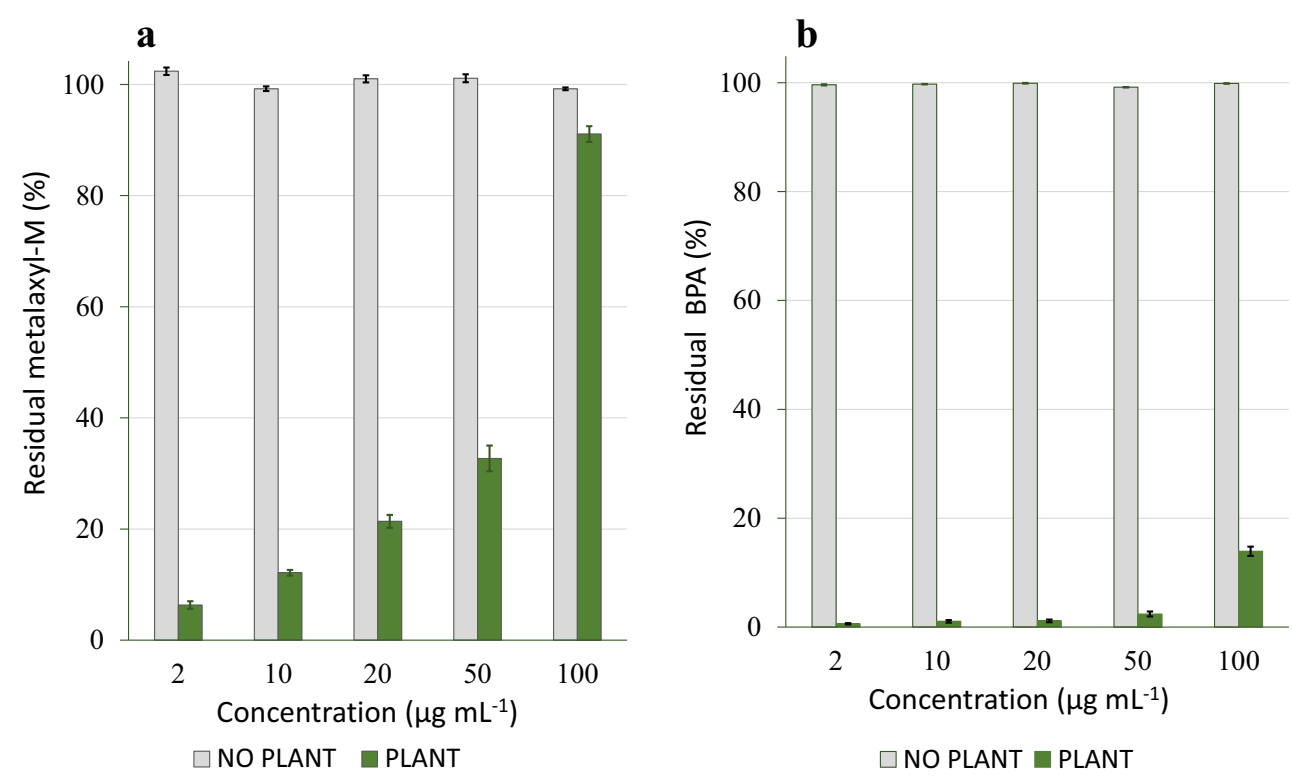

$\square$ NO PLANT $\square$ PLANT 


\section{Removal of the compounds from soil column}

\section{Leaching and disappearance in soil}

During the experimental period, the five molecules underwent a series of processes in the soil, including absorption by plants, adsorption on the solid fraction, leaching, and degradation. Removal by plants, aside from absorption, was possibly also due to enhanced microbiological degradation stimulated by root exudates (rhizodegradation or phytostimulation), although in this work, the two processes were not investigated individually.

As expected, both materials, especially $\mathrm{BC}$, improved the capacity of soil to retain the molecules in the upper layers, contrasting their leaching. In soil + BC treatments, the maximum amounts of all compounds were found in the $0-5 \mathrm{~cm}$ layer (Figs. 4 and 5). Compared with bare soil, the presence of plants did not change substantially the distribution of the chemicals along the soil profile. This could be attributed to the poor extension of the roots both for the short growth time and for the stress of the multi-contamination of soil. Anyway, in various cases, the presence of plants significantly decreased the residual compounds, especially in the upper $0-5 \mathrm{~cm}$ layer where most of the roots are present (Figs. 4 and 5).
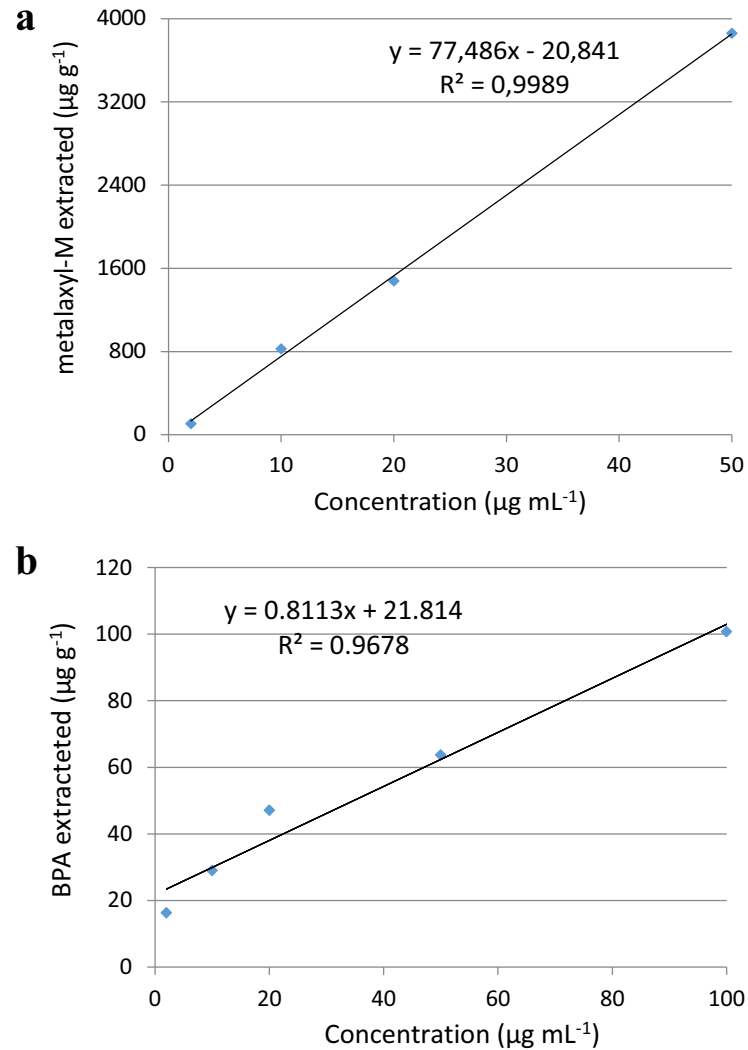

Among the five compounds, metalaxyl-M was only found in the deepest layer $(15-25 \mathrm{~cm})$, albeit in very small quantities (Fig. 4a). The relatively high water solubility and mobility of this molecule can account for its overall leaching. Compared with unamended soil, the addition of $\mathrm{CM}$ and, especially, $\mathrm{BC}$ altered the distribution of this compound along the soil profile, counteracting its downward movement (Fig. 4a). Fernandes et al. (2003) reported that the adsorption of metalaxyl in soil was affected mainly by the organic fraction. The adsorption capacity of a CM-based biomixture for metalaxyl-M was much higher than that of the soil (Karanasios et al. 2010). Gámiz et al. (2016), studying the effects of an olive-mill waste $\mathrm{CM}$ and its $\mathrm{BC}$ on metalaxyl movement in soil, concluded that although both materials were able to limit metalaxyl leaching, $\mathrm{BC}$ was much more effective. In a recent study, Parlavecchia et al. (2019) compared the adsorption capacity of a nonamended soil and the same soil amended with $2 \%(\mathrm{w} / \mathrm{w})$ of two types of $\mathrm{CM}$ or $\mathrm{BC}$ and found that, on average, the retention capacity of the soil for metalaxyl-M was, respectively, twice or four times higher in the amended soil.

Hemp plants were able to significantly reduce residual metalaxyl-M in the upper layers of the soil, compared with bare soil, reducing the risk of leaching (Fig. 4a). That was expected considering that most of the roots were located approximately in the upper $10 \mathrm{~cm}$ of soil. When the whole soil
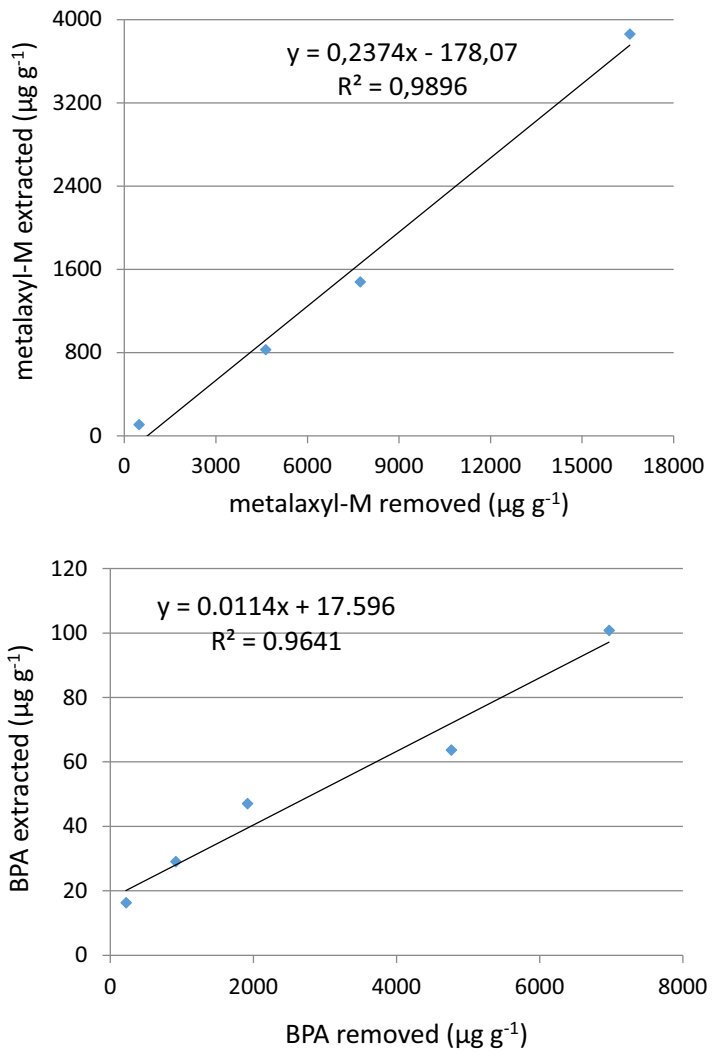

Fig. 3 Correlations between the compound concentration added (left) or that removed by plants (right, $\mu \mathrm{g} \mathrm{g}^{-1}$ of dry biomass) and the compound accumulated in hemp biomass ( $\mu \mathrm{g} \mathrm{g}^{-1}$ of dry biomass). a Metalaxyl-M. b BPA 
column was considered, after 25 days from the start of the experiments, on average, $8 \%$ of the amount of metalaxyl disappeared in bare soil, likely due to degradation, and no significant influence of the amendments was observed (Table 3). The presence of hemp reduced noticeably the residual metalaxyl-M in the column, especially in not amended soil where up to $26 \%$ of the compound disappeared (Table 3). In planted soil, the removal of this compound was significantly $(P \leq 0.05)$ reduced by both amendments (Table 3$)$. We can hypothesize that the retention of metalaxyl-M by $\mathrm{CM}$ and, especially, $\mathrm{BC}$ hindered the uptake of this compound by the plants.

The leaching of metribuzin down to $15 \mathrm{~cm}$ can be attributed to its relatively low hydrophobicity. The presence of $\mathrm{CM}$ and, especially, $\mathrm{BC}$ favored the retention of this molecule in the upper layer (Fig. 4b). In soil + BC treatment, almost all residual metribuzin was found in the upper $10 \mathrm{~cm}$ of soil, especially in the top layer $(0-5 \mathrm{~cm})$, where its concentration was $5.84 \mu \mathrm{g}$ $\mathrm{g}^{-1}$ (Fig. 4b). Karanasios et al. (2010) reported the relevant contribution of $\mathrm{CM}$ to retain metribuzin, resulting in the Freundlich sorption constant $\left(\mathrm{Kf}_{\text {ads }}\right)$ of a compost-containing biomixture up to three times higher than that of the soil. In soil
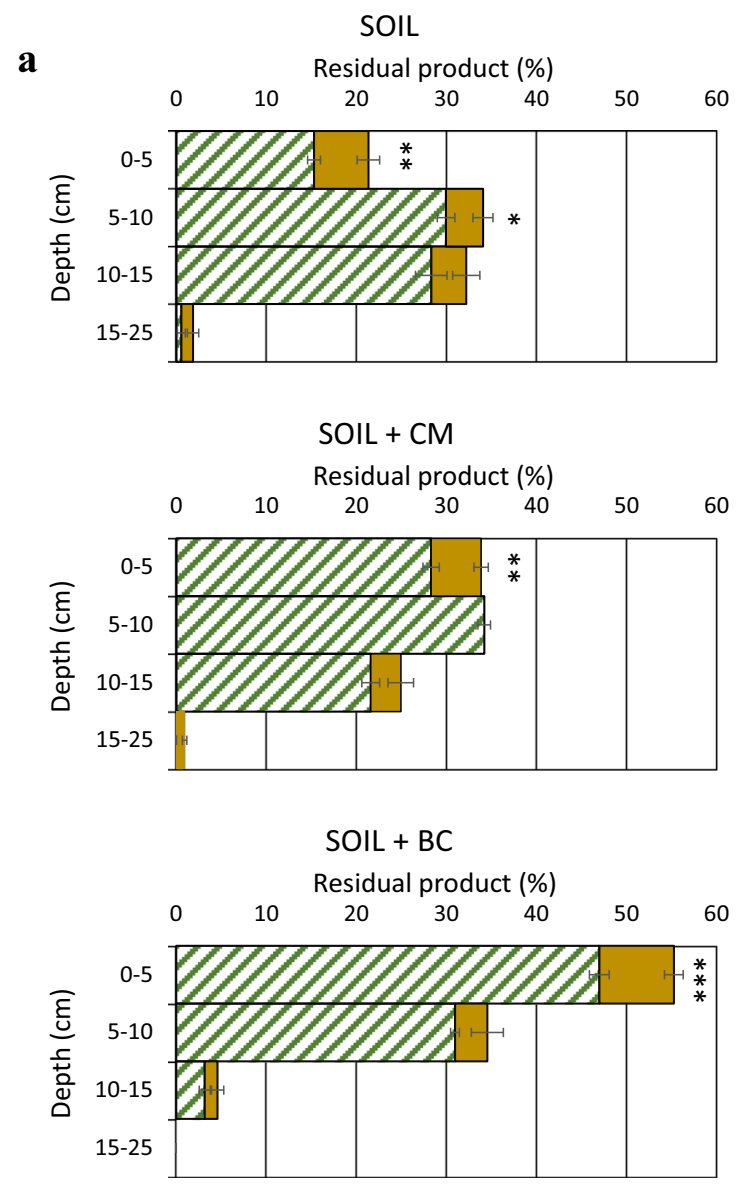

Fig. 4 Residual metalaxyl-M (a) and metribuzin (b) at different depths of soil only and soil added with $2.5 \%(\mathrm{w} / \mathrm{w})$ of $\mathrm{CM}$ or BC. Whole bar: bare soil; striped portion of the bar: soil with plants. Means were separated by the column tests, Lopez-Pineiro et al. (2013) reported that CM amendment of soil noticeably increased the capacity of soil to retain metribuzin, reducing its leaching and also favoring degradation. It has been recently demonstrated that $\mathrm{CM}$ and, especially, $\mathrm{BC}$ have a remarkable capacity to sorb metribuzin, allowing to speculate that the addition of composted and carbonaceous materials to the soil may greatly enhance the adsorption of this compound (Loffredo et al. 2019).

The presence of plants did not modify the trend of metribuzin along the soil profile but significantly reduced its quantities at various depths of all treatments, especially in the upper $5 \mathrm{~cm}$ of soil where most of the roots were present (Fig. 4b). On average, for the treatments, in 25 days, hemp removed a significant amount of metribuzin from the whole column, resulting more than twice that disappeared in bare soil (Table 3). This can be reasonably attributed to both plant uptake and enhanced microbiological degradation. The presence of $\mathrm{CM}$ and $\mathrm{BC}$ did not affect significantly metribuzin disappearance neither in bare soil nor in soil with hemp (Table 3). This is in contrast with what reported by Mehdizadeh et al. (2019), who found that a green CM could promote the decay of this herbicide in soil, mostly for the
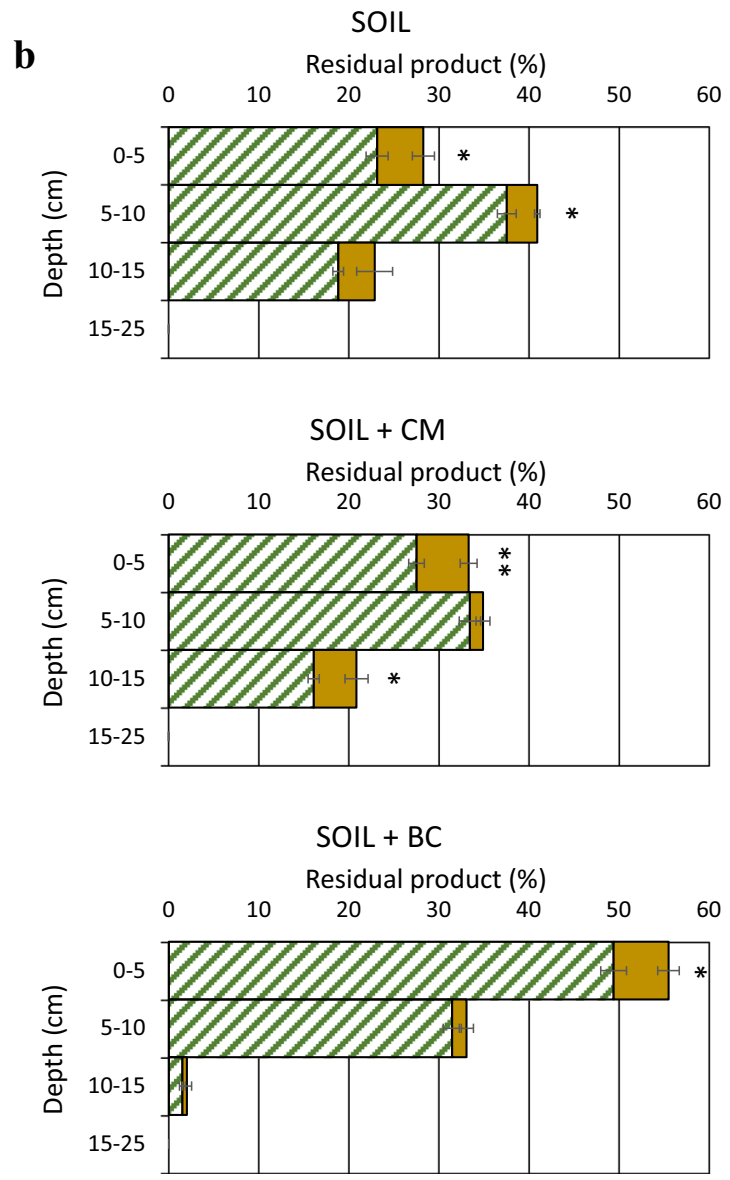

least significant difference (LSD) test. $* P \leq 0.05, * * P \leq 0.01$, $* * * P \leq 0.001$. The horizontal line on each bar indicates the standard error $(n=3)$ 
a

SOIL

Residual product (\%)

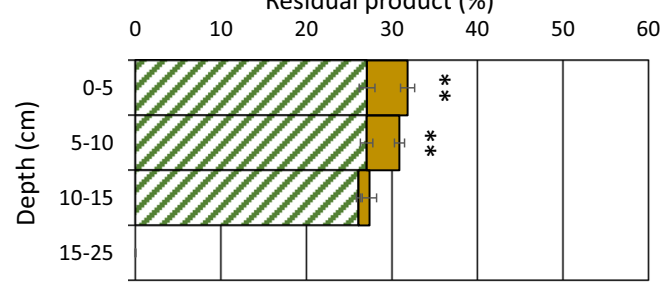

$\mathrm{SOIL}+\mathrm{CM}$

Residual product (\%)

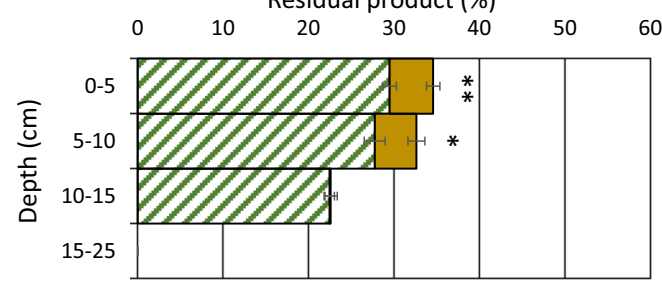

$\mathrm{SOIL}+\mathrm{BC}$

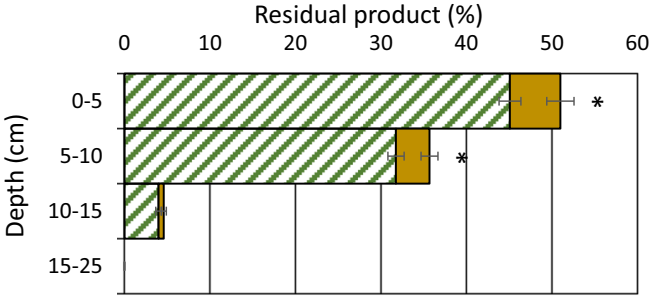

c

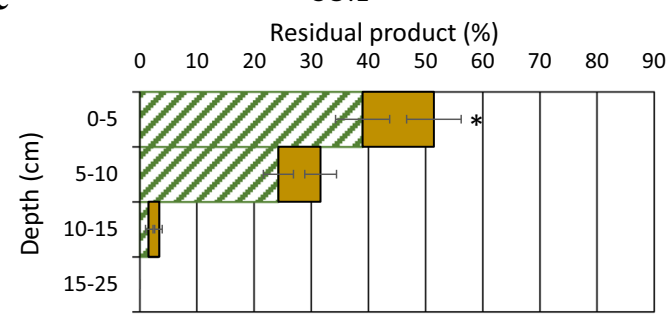

$\mathrm{SOIL}+\mathrm{CM}$

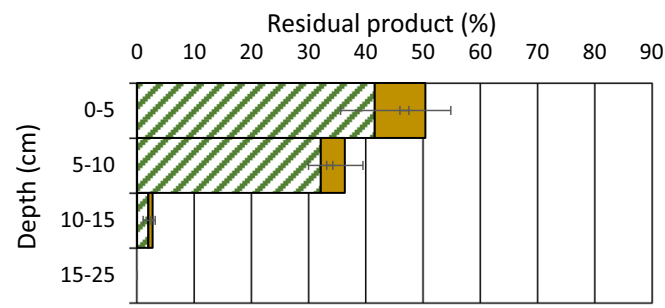

SOIL + BC

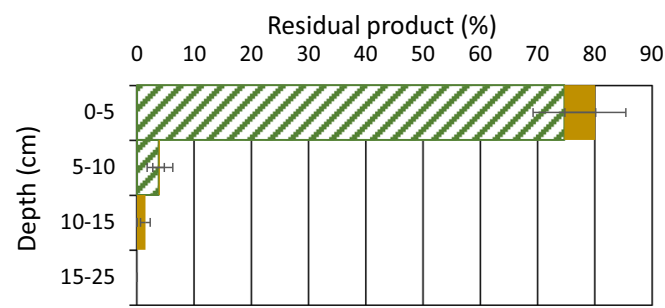

b

SOIL

Residual product (\%)

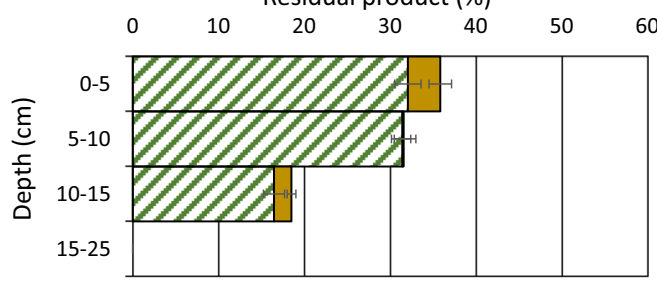

$\mathrm{SOIL}+\mathrm{CM}$

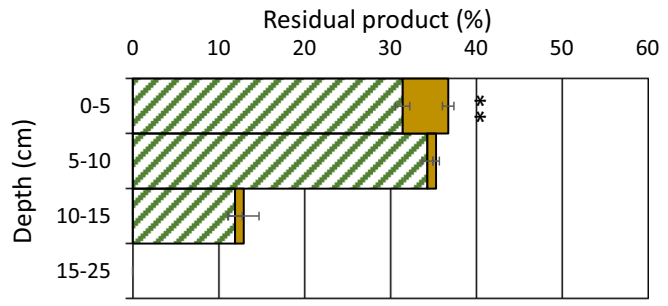

$\mathrm{SOIL}+\mathrm{BC}$

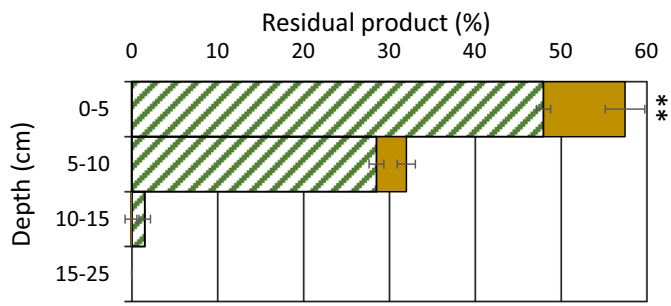


Fig. 5 Residual BPA (a), E2 (b), and OP (c) at different depths of soil only and soil added with $2.5 \%(\mathrm{w} / \mathrm{w})$ of CM or BC. Whole bar: bare soil; striped portion of the bar: soil with plants. Means were separated by the least significant difference (LSD) test. $* P \leq 0.05, * * P \leq 0.01, * * * P \leq 0.001$. The horizontal line on each bar indicates the standard error $(n=3)$

stimulation of degrading microbes. Benoit et al. (2007) studied the pathways of metribuzin degradation in soil and concluded that biodegradation is the foremost process.

Residual BPA was uniformly distributed along the first $15 \mathrm{~cm}$ of soil only, whereas it accumulated mainly in the upper layers $(0-10 \mathrm{~cm})$ in soil + BC (Fig. 5a). Also for this compound, the retention and transport in soil is strictly affected by the level of soil organic matter (Shi et al. 2019). Hemp plants did not modify the vertical distribution of BPA in soil but were able to significantly reduce residual BPA in the upper $10 \mathrm{~cm}$

Table 3 Effects of treatment, plants, and their interaction on the amount of compound disappeared in 25 days in the whole soil column. Data are expressed as percentage of the initial amount added per column

\begin{tabular}{|c|c|c|c|}
\hline Treatment & Bare soil & Soil + plants & Average \\
\hline \multicolumn{4}{|c|}{ Metalaxyl-M; 0.05P: 5.9 } \\
\hline Soil & $11.2 \pm 1.3$ & $26.0 \pm 2.4$ & $18.6 \mathrm{a}$ \\
\hline Soil + CM & $7.2 \pm 1.3$ & $16.0 \pm 2.2$ & $11.6 \mathrm{~b}$ \\
\hline Soil + BC & $5.6 \pm 2.2$ & $18.9 \pm 1.1$ & $12.3 \mathrm{~b}$ \\
\hline Average & $8.0 \mathrm{~b}$ & $20.3 \mathrm{a}$ & \\
\hline \multicolumn{4}{|l|}{ Metribuzin $^{\mathrm{b}}$} \\
\hline Soil & $7.9 \pm 0.7$ & $20.5 \pm 0.8$ & 14.2 \\
\hline Soil + CM & $10.9 \pm 1.4$ & $22.9 \pm 1.5$ & 16.9 \\
\hline Soil + BC & $9.4 \pm 2.0$ & $17.6 \pm 0.9$ & 13.5 \\
\hline Average & $9.4 \mathrm{~b}$ & $20.3 \mathrm{a}$ & \\
\hline \multicolumn{4}{|l|}{$\mathrm{BPA}^{\mathrm{b}}$} \\
\hline Soil & $10.0 \pm 2.0$ & $19.1 \pm 1.9$ & 14.5 \\
\hline Soil + CM & $10.2 \pm 0.9$ & $20.3 \pm 1.4$ & 15.3 \\
\hline Soil + BC & $8.8 \pm 2.3$ & $19.2 \pm 1.4$ & 14.0 \\
\hline Average & $9.6 \mathrm{~b}$ & $19.5 \mathrm{a}$ & \\
\hline \multicolumn{4}{|l|}{$\mathrm{E} 2^{\mathrm{b}}$} \\
\hline Soil & $14.0 \pm 2.6$ & $20.0 \pm 1.4$ & 17.0 \\
\hline Soil + CM & $14.9 \pm 2.4$ & $22.3 \pm 1.2$ & 18.6 \\
\hline Soil + BC & $9.5 \pm 4.0$ & $21.9 \pm 1.1$ & 15.7 \\
\hline Average & $12.8 \mathrm{~b}$ & $21.4 \mathrm{a}$ & \\
\hline \multicolumn{4}{|c|}{ OP; $0.05 \mathrm{P}: 7.5^{\mathrm{a}}$} \\
\hline Soil & $13.7 \pm 2.5$ & $35.2 \pm 5.3$ & $24.4 \mathrm{a}$ \\
\hline Soil + CM & $13.7 \pm 4.4$ & $24.4 \pm 8.2$ & $19.0 \mathrm{~b}$ \\
\hline Soil + BC & $14.4 \pm 2.3$ & $21.5 \pm 6.1$ & $18.0 \mathrm{~b}$ \\
\hline Average & $13.9 \mathrm{~b}$ & $27.0 \mathrm{a}$ & \\
\hline
\end{tabular}

Significant differences between means are shown by different letters according to the least significant differences (LSD) test at $P \leq 0.05$

${ }^{\text {a }}$ Least significant difference for the interaction of treatment $\times$ plants at $P$ $\leq 0.05$

${ }^{\mathrm{b}}$ Letters or LSD value are not reported for not significant factors or interactions of the soil, compared with bare soil, contrasting leaching (Fig. 5a). Maximum residual BPA was found in the upper $5 \mathrm{~cm}$ of soil $+\mathrm{BC}$ and soil $+\mathrm{BC}+$ plants, where BPA concentrations were, respectively, 5.37 and $4.75 \mu \mathrm{g} \mathrm{g}^{-1}$. Statistical analysis of the data of BPA disappearance in soil excluded the importance of the addition of CM or BC both in bare and in planted soil, whereas plants did play a relevant role in the process (Table 3). Our results are in agreement with what reported by $\mathrm{Xu}$ et al. (2015) who found that $\mathrm{BC}$ noticeably reduced BPA mobility and leaching in soil but did not affect its degradation.

Both E2 and OP were the least mobile in the soil, with little changes between soil only and soil + CM. (Fig. 5b, c). A high retention of the two EDCs in soil, and especially the contribution of $\mathrm{BC}$, was expected on the basis of the $\log K_{\mathrm{ow}}$ of E2 (3.90) and OP (5.50). At the end of experiments, residual E2 in the 10-15 cm layer of soil only and soil + CM was lower or much lower than that found for BPA and the two pesticides (Fig. 5b). Tong et al. (2019) showed that adsorption of E2 in soil was highly depended on mineral-organic complexes of soil. Hemp did not alter substantially the distribution of E2 along the soil profile; however, it significantly reduced its residue in the upper $0-5 \mathrm{~cm}$ layer of amended soil (Fig. 5b). On average, for the treatments, the disappearance of E2, after 25 days, in the whole soil column, although not affected by the amendment, was much greater in planted soil $(21.4 \%)$ than in bare soil (12.8\%) (Table 3$)$, indicating a marked contribution of hemp in the loss of this compound. It is reasonable that both plant uptake and enhanced microbiological degradation played a role in E2 disappearance.

Almost all residual OP accumulated in the upper $10 \mathrm{~cm}$ of soil only and soil $+\mathrm{CM}$ or even in the upper $5 \mathrm{~cm}$ of soil $+\mathrm{BC}$, evidencing the very low potential of OP to leach (Fig. 5c). Compared with bare soil, planted soil showed a similar vertical distribution of OP, reducing significantly the residual compound only in the upper $5 \mathrm{~cm}$ of the unamended soil but excluding OP presence below $10 \mathrm{~cm}$ in the treatment soil + BC (Fig. 5c). At the end of experiments, the lowest quantity of $\mathrm{OP}$ in the whole soil column was measured in the treatment soil + plants (Table 3). Although neither CM nor BC affected OP disappearance in bare soil, both materials significantly decreased OP removal by hemp (Table 3). Possible explanations for this could be both the strong retention of OP by the materials that reduced OP bioavailability and competed with the possible root uptake and the lesser availability of root exudates for the rhizodegradation process. In fact, even some plant metabolites, such as phenolic acids, might have been adsorbed by the materials and be therefore less available for soil microorganisms. Zhou (2006) evidenced the importance of organic colloids in controlling the environmental fate of OP. The strong sorption of OP on a red spruce BC was demonstrated (Loffredo and Taskin 2017). 
Results obtained in these soil column experiments evidenced the crucial role of the upper 5-cm layer of soil, where most of the rhizosphere is located and most of the aerobic processes occur. Therefore, we tried to relate the residual compounds in this layer, at the end of the experiments. with important properties of the molecules. Plotting residual compounds in the upper $5 \mathrm{~cm}$ of soil versus the corresponding $\log K_{\mathrm{ow}}$, significant positive correlations $(P \leq 0.05)$ were found only for unamended soil, both bare and planted. This indicated that the leaching of the five compounds in soil was inversely related to their hydrophobicity and that the addition of CM or BC could alter this law, possibly because it acted simultaneously on more processes, like retention, movement, plant uptake, and degradation, which are not strictly related to hydrophobicity. Correlations between the residual compound in the upper $5 \mathrm{~cm}$ of soil, soil + CM and soil + BC (bare soil), and the corresponding organic matter $(\mathrm{OM})$ content were significant $(P \leq 0.05)$ for metribuzin, BPA and E2. In this case, let us assume that, for the latter compounds, retention was the prominent process to contrast leaching or that both leaching and degradation were influenced with similar extent and trend. Differently, in the cases of the very soluble metalaxyl-M and the highly hydrophobic OP, the OM content might have influenced differently leaching and biodegradation or it was not the foremost property.

Finally, the plant removal of each compound from the whole column, calculated as the difference between the amount which disappeared on average in planted soil and bare soil (Table 3), and excluding OP, was inversely related to the hydrophobicity of the molecule, being the least hydrophobic the most removed. In the case of OP, it is possible that its overall surface localization, which coincided with the zone of the greatest root expansion, favored plant removal beyond what was expected. Based on the hydrophobicity of OP and the absence of OP residues in plant tissues (see the "Plant response and compound accumulation" section), it is plausible that OP removal occurred mainly or exclusively through rhizodegradation.

\section{Plant response and compound accumulation}

Hemp plants grown for 25 days in multi-contaminated soil not amended or amended with $\mathrm{CM}$ or $\mathrm{BC}$ did not show visual alterations, except a delayed growth, compared with plants grown in uncontaminated soil (control). Biometric data showed lower root and shoot elongation and fresh and dry biomass, denoting an unquestionable toxicity of the chemical mixture on plants (Fig. 6). Phytotoxicity of these compounds, individually applied, was already observed in previous studies. Teixeira et al. (2011) reported root depression and other damages on plant $S$. nigrum L. exposed at concentrations $\geq 12.5 \mu \mathrm{g}$ $\mathrm{g}^{-1}$ of the sole metalaxyl in 28 days. Doses of 4.6 and $46 \mu \mathrm{g} \mathrm{g}^{-1}$ of BPA altered the root morphology and
Fig. 6 Effects of the substrate on the elongation and dry mass of hemp plants grown in soil columns compared with controls (plants grown in not contaminated soil). Means were separated by the least significant difference (LSD) test. $* P \leq 0.05, * * P \leq 0.01$, $* * * P \leq 0.001$. The vertical line on each bar indicates the standard error $(n=3)$
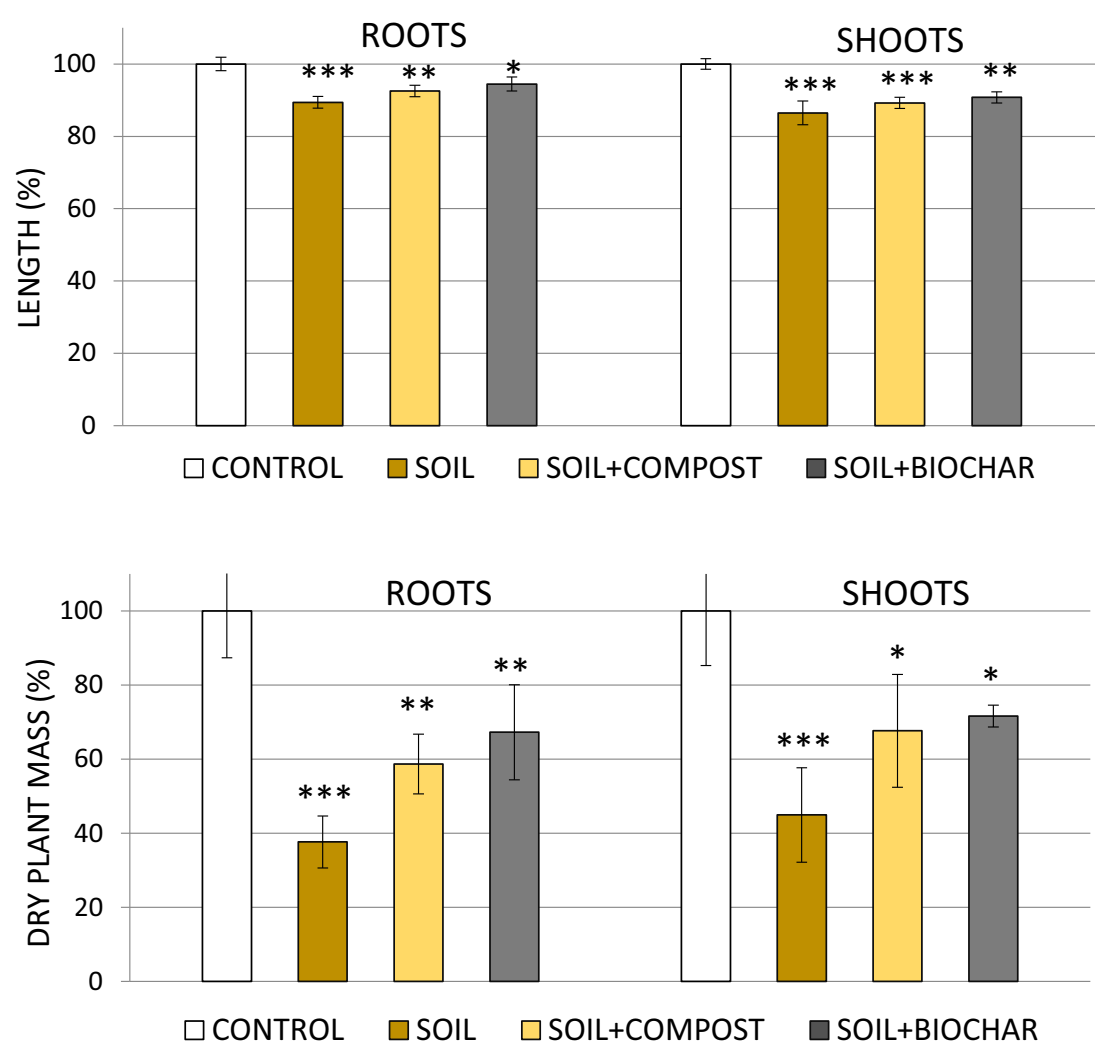
markedly reduced fresh weight of 16-day seedlings of ryegrass and radish (Loffredo et al. 2010).

However, contaminant toxicity on hemp was significantly attenuated by the presence of CM and, especially, $\mathrm{BC}$ which, in the order, increased the dry weight of roots by 55 and $78 \%$ and of shoots by 51 and $59 \%$, compared with soil only (Fig. 6). These results clearly indicated the occurrence of plant-protective effects by both materials.

As already observed in germination experiments, hemp showed a great ability to absorb metalaxyl-M from the soil and accumulate it, especially in the aerial part (Fig. 7). The maximum compound accumulation was measured in the shoots
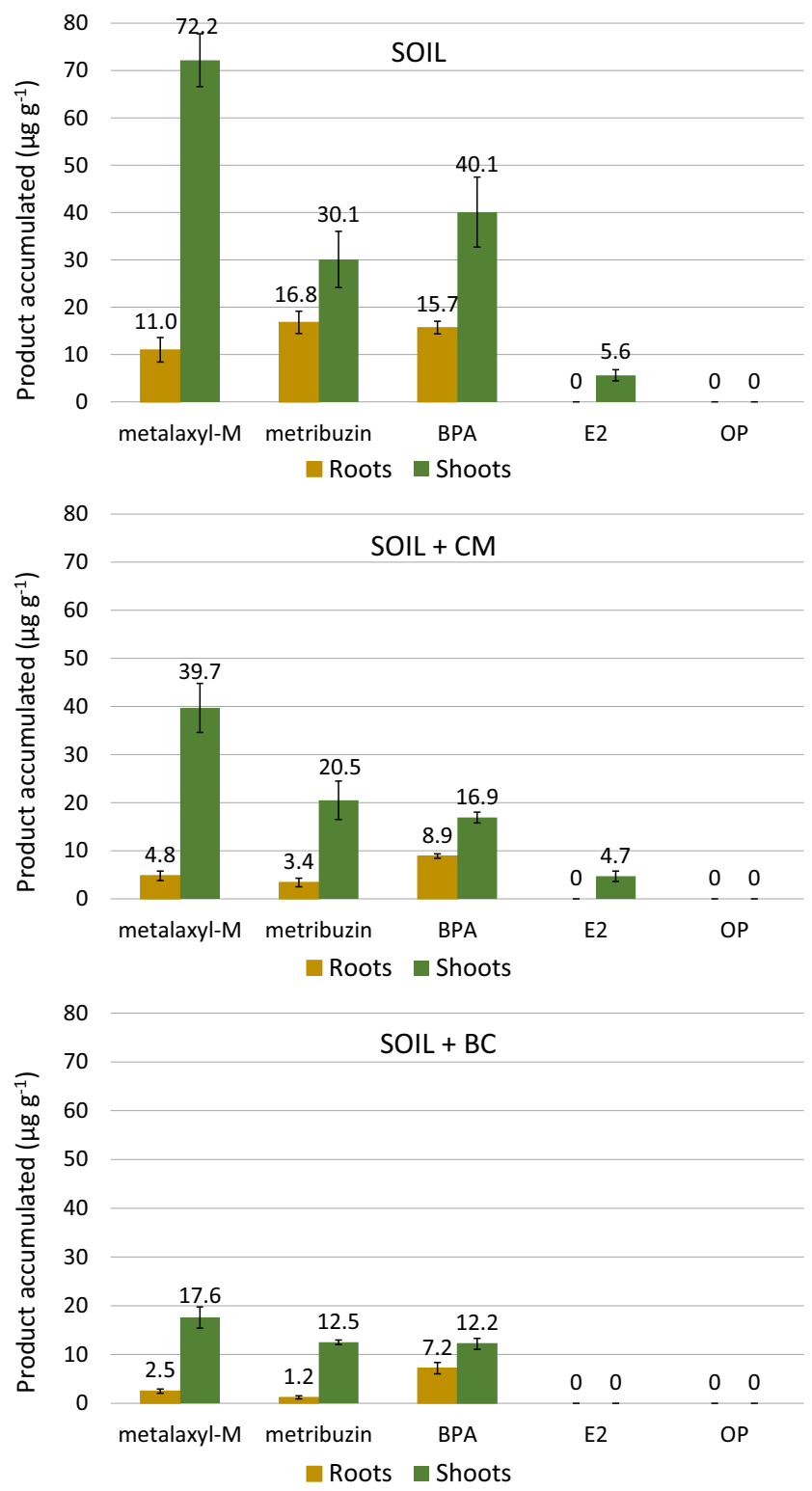

Fig. 7 Compound accumulation in root and shoot dry mass of hemp grown for 25 days in columns filled with soil only and soil added with $\mathrm{CM}$ or $\mathrm{BC}$. The vertical line on each bar indicates the standard error $(n=3)$ of the plants grown in unamended soil, being $72 \mu \mathrm{g} \mathrm{g}^{-1}$ (Fig. 7). Similar to what reported by Teixeira et al. (2011), a much lower accumulation of metalaxyl-M occurred in hemp roots. The preferential translocation of this compound from roots to shoots can depend on the low hydrophobicity of this compound that allows high mobility into the vascular system of plants. Kubicki et al. (2019), studying the dynamic of metalaxyl in tomato, reported that the compound was readily taken up by the roots with the normal water absorption and translocated uniformly to the aerial organs through the xylematic vessels. Very recently, Gong et al. (2020) found that metalaxyl-M translocated rapidly in chrysanthemum plants where it accumulated mainly in the leaves and ascribed that to the relatively low $\log K_{\mathrm{ow}}$.

In soil $+\mathrm{CM}$ and soil $+\mathrm{BC}$ treatments, plants accumulated less metalaxyl-M and always more in the shoots than in the roots (Fig. 7). These results confirmed the evidence of a straight relationship between the quantity of compound removed and that of compound accumulated. Anyway, if on the one hand $\mathrm{CM}$ or $\mathrm{BC}$ hindered the removal of metalaxyl$\mathrm{M}$ by plants, on the other hand, they clearly exerted an antitoxic activity that was crucial for allowing plants to tolerate heavily polluted soil. The percentage of metalaxyl-M accumulated in plants, compared with that removed from the soil, was very low and minimum in soil $+\mathrm{BC}$ treatment (Table 4 ). This suggested that $\mathrm{BC}$, in addition to influencing absorption and accumulation, could also affect the plant transformation of this molecule. Further studies could elucidate this aspect.

The herbicide metribuzin accumulated in plants to a lesser extent than metalaxyl-M and once more especially in shoots (Fig. 7). Moreover, the extent of accumulation depended on the soil treatment. Preferential accumulation of metribuzin into the aerial plant organs might depend on the relatively low hydrophobicity of this compound and the high mobility into the plant vascular system. The lowest amounts of metribuzin $\left(12.5 \mu \mathrm{g} \mathrm{g}^{-1}\right)$ were found in the roots and shoots of plants grown in the presence of $\mathrm{BC}$ and that might be ascribed to the lower removal by plants of this treatments

Table 4 Percentage of compound accumulated in plant mass compared with the quantity removed by plants from the soil

\begin{tabular}{llll}
\hline Compound & Soil & Soil $+\mathrm{CM}$ & Soil $+\mathrm{BC}$ \\
\hline Metalaxyl-M & $2.34 \pm 0.12 \mathrm{~b}$ & $3.14 \pm 0.21 \mathrm{a}$ & $1.04 \pm 0.10 \mathrm{c}$ \\
Metribuzin & $1.55 \pm 0.10 \mathrm{a}$ & $1.22 \pm 0.18 \mathrm{ab}$ & $1.13 \pm 0.03 \mathrm{~b}$ \\
BPA & $2.52 \pm 0.09 \mathrm{a}$ & $1.66 \pm 0.09 \mathrm{~b}$ & $1.32 \pm 0.09 \mathrm{c}$ \\
E2 & $0.41 \pm 0.12$ & $0.41 \pm 0.12$ & n.d. \\
OP & n.d. & n.d. & n.d. \\
\hline
\end{tabular}

Data were analyzed by ANOVA and means were separated by LSD test at $P \leq 0.05(n=3)$

n.d. not detected 
(Fig. 7). The percentage of metribuzin accumulated in plants compared with that removed was generally very low and significantly lower in soil $+\mathrm{BC}$, compared with soil only (Table 4). Also for this compound, it seemed that BC somehow stimulated the transformation of metribuzin into the plant tissues.

Evidence of the capacity of hemp to absorb BPA from soil was confirmed by the significant product accumulation found in the shoots and roots of hemp (Fig. 7). A lower amount of BPA was extracted from hemp roots than from shoots (Fig. 7). Compared with metalaxyl and metribuzin, the ratio between the compound accumulated in roots and that accumulated in shoots was higher for BPA. That might depend on the higher hydrophobicity of this molecule that made translocation more difficult. Also for BPA, plant metabolization seemed to be influenced by the addition of the materials, in which accumulation is lower in the presence of $\mathrm{CM}$ and, especially, $\mathrm{BC}$ (Table 4).

The limited amount of E2 found only in the plant shoots of unamended soil and soil + CM (Fig. 7) can be ascribed to the preferential transport of this molecule to the upper organs. Chuang et al. (2019) demonstrated that E2 was rapidly and conspicuously absorbed by lettuce but its accumulation in roots was negligible because the compound was preferentially transported upwards to shoots with the water flow. The same authors reported a very rapid metabolization of E2 by plants, mainly in the green organs, with the mass recovery of less than $25 \%$ after only $48 \mathrm{~h}$ of exposure (Chuang et al. 2019). Anyway, considering the quantity of E2 removed on average by plants (Table 2) and the very low percentage of contaminant accumulated in plant tissues (Table 4), we can hypothesize that another process might have contributed to these results, namely rhizodegradation. Root exudates released by hemp, and localized especially in the upper layer where E2 was more concentrated, might have stimulated the activity of microorganisms involved in E2 degradation. Furthermore, the presence of $\mathrm{BC}$ in the soil might have promoted rhizodegradation and that could be the reason why E2 was not extracted from plants grown in soil $+\mathrm{BC}$. A recent study demonstrated that Bjerkandera adusta, a common soil-resident fungus, has a relevant capacity to degrade $\mathrm{E} 2$ and that this activity is even higher in the presence of BC (Loffredo et al. 2016).

The OP was the only molecule that was not found in the plants, either in roots or in shoots, of all treatments. The hydrophobic character of this molecule must have played an important role in reducing the mobility of this compound both in soil and in plants. Comparing residual OP in bare and planted soil (Table 3), it was evident that an appreciable disappearance of OP could be ascribed to hemp. To explain these results, we can appeal to at least two reasons. The first is that hemp absorbed OP and efficiently transformed it. In fact, although the high $\log K_{\text {ow }}$ (5.50) of OP seems to hinder plant absorption, it was demonstrated that plants like Portulaca oleracea can efficiently absorb and metabolize OP and other EDCs, including BPA and E2 (Imai et al. 2007). The second is rhizodegradation. Similar to what possibly happened for E2, the presence of plants and their root exudates might have stimulated microbial degradation of OP in the soil. That might have been even more important for OP than E2, considering the very superficial localization of OP in the soil. Phenolic EDCs, such as OP, can be effectively degraded by soilresident ligninolytic fungi (Loffredo et al. 2016).

\section{Conclusions}

Seedlings of Cannabis sativa L. proved to be very effective in removing individually the fungicide metalaxyl-M and the endocrine disruptor BPA from water. Despite that both molecules showed toxicity on seedlings, their removal was relevant up to a concentration of $50 \mu \mathrm{g} \mathrm{mL}^{-1}$ of metalaxyl-M and $100 \mu \mathrm{g} \mathrm{mL}^{-1}$ of BPA. Residual compounds accumulated in hemp tissues in 7 days were much lower than the amounts removed from the medium, indicating an efficient metabolization of these molecules. When hemp was allowed to germinate and grow in columns filled with a soil multicontaminated with metalaxyl-M, metribuzin, BPA, E2, and OP, despite the toxic effects, the plant once more showed a noticeable remediation capacity. The addition to the soil of materials like $\mathrm{CM}$ and $\mathrm{BC}$ relieved, at least partly, the phytotoxicity stress, albeit the plants removed less quantities of metalaxyl-M and OP. Both CM and, especially, BC were able to modify the leaching pattern of the compounds along the soil profile, favoring their localization in the upper layers, compared with unamended soil. Among the five compounds, only OP was not found in the plants, whereas the others, especially the less hydrophobic pesticides, were absorbed by hemp and accumulated mainly in the aboveground organs. A very large part of the compounds taken up by plants was transformed in plant tissues. The overall findings of this study suggest that hemp is a promising candidate for practical phytoremediation of wastewater and soil from pesticides and endocrinedisrupting chemicals.

Acknowledgments The authors thank the Italian Composting and Biogas Association (CIC) for providing the green compost and Emporio Canapuglia S.a.s., Conversano, Italy, for providing hemp seeds. The authors are also grateful to the anonymous reviewers for their valuable suggestions.

Funding Open access funding provided by Università degli Studi di Bari Aldo Moro within the CRUI-CARE Agreement. This work was funded by Università degli Studi di Bari Aldo Moro, Italy.

Open Access This article is licensed under a Creative Commons Attribution 4.0 International License, which permits use, sharing, adaptation, distribution and reproduction in any medium or format, as long as 
you give appropriate credit to the original author(s) and the source, provide a link to the Creative Commons licence, and indicate if changes were made. The images or other third party material in this article are included in the article's Creative Commons licence, unless indicated otherwise in a credit line to the material. If material is not included in the article's Creative Commons licence and your intended use is not permitted by statutory regulation or exceeds the permitted use, you will need to obtain permission directly from the copyright holder. To view a copy of this licence, visit http://creativecommons.org/licenses/by/4.0/.

\section{References}

Arias-Estévez M, López-Periago E, Martínez-Carballo E, Simal-Gándara J, Mejuto JC, García-Rio L (2008) The mobility and degradation of pesticides in soils and the pollution of groundwater resources. Agric Ecosyst Environ 123:247-260. https://doi.org/10.1016/j.agee.2007. 07.011

Baronti C, Curini R, D’Ascenzo G, Di Corcia A, Gentili A, Samperi R (2000) Monitoring natural and synthetic estrogens at activated sludge sewage treatment plants and in a receiving river water. Environ Sci Technol 34:5059-5066. https://doi.org/10.1021/ es001359q

Benoit P, Perceval J, Stenrod M, Moni C, Eklo OM, Barriuso E, Sveistrup T, Kvaerner J (2007) Availability and biodegradation of metribuzin in alluvial soils as affected by temperature and soil properties. Weed Res 47:517-526. https://doi.org/10.1111/j.1365-3180.2007.00589. $\mathrm{x}$

Campbell CG, Borglin SE, Green FB, Grayson A, Wozei E, Stringfellow WT (2006) Biologically directed environmental monitoring, fate, and transport of estrogenic endocrine disrupting compounds in water: a review. Chemosphere 65:1265-1280. https://doi.org/10.1016/ j.chemosphere.2006.08.003

Chirakkara RA, Reddy KR (2015) Biomass and chemical amendments for enhanced phytoremediation of mixed contaminated soils. Ecol Eng 85:265-274. https://doi.org/10.1016/j.ecoleng.2015.09.029

Chuang Y-H, Liu C-H, Sallacha JB, Hammerschmidt R, Zhang W, Boyd SA, Li H (2019) Mechanistic study on uptake and transport of pharmaceuticals in lettuce from water. Environ Int 131:104976. https:// doi.org/10.1016/j.envint.2019.104976

Diamanti-Kandarakis E, Bourguignon JP, Giudice LC, Hauser R, Prins GS, Soto AM, Zoeller RT, Gore AC (2009) Endocrine-disrupting chemicals: an Endocrine Society scientific statement. Endocr Rev 30:293-342. https://doi.org/10.1210/er.2009-0002

Fernandes MC, Cox L, Hermosín MC, Cornejo J (2003) Adsorptiondesorption of metalaxyl as affecting dissipation and leaching in soils: role of mineral and organic components. Pest Manag Sci 59: 545-552. https://doi.org/10.1002/ps.664

Ferrara G, Loffredo E, Senesi N (2006) Phytotoxic, clastogenic and bioaccumulation effects of the environmental endocrine disruptor bisphenol A in various crops grown hydroponically. Planta 223: 910-916. https://doi.org/10.1007/s00425-005-0147-2

Gámiz B, Pignatello JJ, Cox L, Hermosín MC, Celis R (2016) Environmental fate of the fungicide metalaxyl in soil amended with composted olive-mill waste and its biochar: an enantioselective study. Sci Total Environ 54:776-783. https://doi.org/10.1016/j. scitotenv.2015.09.097

Gasco G, Alvarez ML, Paz-Ferreiro J, Méndez A (2019) Combining phytoextraction by Brassica napus and biochar amendment for the remediation of a mining soil in Riotinto (Spain). Chemosphere 231: 562-570. https://doi.org/10.1016/j.chemosphere.2019.05.168

Geissena V, Mol HGJ, Klumpp E, Umlauf G, Nadal M, van der Ploeg M, Zee SEATM, Ritsema CJ (2015) Emerging pollutants in the environment: a challenge for water resource management. Int Soil Water Conserv Res 3:57-65. https://doi.org/10.1016/j.iswcr.2015. 03.002

Gerhardt KE, Huang XD, Glick BR, Greenberg BM (2009) Phytoremediation and rhizoremediation of organic soil contaminants: potential and challenges. Plant Sci 176:20-30. https://doi. org/10.1016/j.plantsci.2008.09.014

Gong W, Jiang M, Zhang T, Zhang W, Liang G, Li B, Hu B, Han P (2020) Uptake and dissipation of metalaxyl-M, fludioxonil, cyantraniliprole and thiamethoxam in greenhouse chrysanthemum. Environ Pollut 257:113499. https://doi.org/10.1016/j.envpol.2019. 113499

Imai S, Shiraishi A, Gamo K, Watanabe I, Okuhata H, Miyasaka H, Ikeda K, Bamba T, Hirata K (2007) Removal of phenolic endocrine disruptors by Portulaca oleracea. J Biosci Bioeng 103:420-426. https://doi.org/10.1263/jbb.103.420

International Biochar Initiative (IBI) (2015) Standardized product definition and product testing guidelines for biochar that is used in soilversion 2.1. Published online by International Biochar Initiative. https://www.biochar-international.org/wp-content/uploads/2018/ 04/IBI_Biochar_Standards_V2.1_Final.pdf. Accessed May 2020

Karanasios E, Tsiropoulos NG, Karpouzas DG, Ehaliotis C (2010) Degradation and adsorption of pesticides in compost-based biomixtures as potential substrates for biobeds in Southern Europe. J Agric Food Chem 58:9147-9156. https://doi.org/10.1021/ jf1011853

Kubicki M, Lamshöft M, Lagojda A, Spiteller M (2019) Metabolism and spatial distribution of metalaxyl in tomato plants grown under hydroponic conditions. Chemosphere 218:36-41. https://doi.org/10. 1016/j.chemosphere.2018.11.069

Linger P, Müssig J, Fischer H, Kobert J (2002) Industrial hemp (Cannabis sativa L.) growing on heavy metal contaminated soil: fibre quality and phytoremediation potential. Ind Crop Prod 16: 33-42. https://doi.org/10.1016/S0926-6690(02)00005-5

Loffredo E, Castellana G, Taskin E (2016) A two-step approach to eliminate pesticides and estrogens from a wastewater and reduce its phytotoxicity: adsorption onto plant-derived materials and fungal degradation. Water Air Soil Pollut 227:188(1-12). https://doi.org/ 10.1007/s11270-016-2883-2

Loffredo E, Gattullo E, Traversa G, Senesi N (2010) Potential of various herbaceous species to remove the endocrine disruptor bisphenol $\mathrm{A}$ from aqueous media. Chemosphere 80:1274-1280. https://doi.org/ 10.1016/j.chemosphere.2010.06.054

Loffredo E, Parlavecchia M, Perri G, Gattullo R (2019) Comparative assessment of metribuzin sorption efficiency of biochar, hydrochar and vermicompost. J Environ Sci Health Part B 54:728-735. https:// doi.org/10.1080/03601234.2019.1632643

Loffredo E, Taskin E (2017) Adsorptive removal of ascertained and suspected endocrine disruptors from aqueous solution using plantderived materials. Environ Sci Pollut Res 24:19159-19166. https:// doi.org/10.1007/s11356-017-9595-z

Lopez-Pineiro A, Pena D, Albarran A, Becerra D, Sanchez-Llerena J (2013) Sorption, leaching and persistence of metribuzin in Mediterranean soils amended with olive mill waste of different degrees of organic matter maturity. J Environ Manag 122:76-84. https://doi.org/10.1016/j.jenvman.2013.03.006

Lu H, Li Z, Fu S, Méndez A, Gascó G, Paz-Ferreiro J (2015) Combining phytoextraction and biochar addition improves soil biochemical properties in a soil contaminated with Cd. Chemosphere 119:209216. https://doi.org/10.1016/j.chemosphere.2014.06.024

Marín-Benito JM, Sánchez-Martín MJ, Ordax JM, Draoui K, Azejjel H, Rodríguez Cruz MS (2018) Organic sorbents as barriers to decrease the mobility of herbicides in soils. Modelling of the leaching process. Geoderma 313:205-216. https://doi.org/10.1016/j.geoderma. 2017.10.033 
McCutcheon SC, Schnoor JL (2003) Phytoremediation: transformation and control of contaminants. Wiley Interscience New York https:// doi.org/10.1007/BF02980279

Mehdizadeh M, Izadi-Darbandi E, Yazdi M, Rastgoo M, MalaekehNikouei B, Nassirli H (2019) Impacts of different organic amendments on soil degradation and phytotoxicity of metribuzin. Int $\mathrm{J}$ Recycl Org Waste Agric 8:113-121. https://doi.org/10.1007/ s40093-019-0280-8

Morillo E, Villaverde J (2017) Advanced technologies for the remediation of pesticide-contaminated soils. Sci Total Environ 586:576597. https://doi.org/10.1016/j.scitotenv.2017.02.020

Parlavecchia M, D’Orazio V, Loffredo E (2019) Wood biochars and vermicomposts from digestate modulate the extent of adsorptiondesorption of the fungicide metalaxyl-m in a silty soil. Environ Sci Pollut Res 26:35924-33593. https://doi.org/10.1007/s11356-01906729-Z

Paz-Ferreiro J, Lu H, Fu S, Méndez A, Gascó G (2014) Use of phytoremediation and biochar to remediate heavy metal polluted soils: a review. Solid Earth 5:65-75. https://doi.org/10.5194/se-565-2014

PubChem open chemistry database at the National Institutes of Health (NIH), U.S. National Library of Medicine. https://pubchem.ncbi. nlm.nih.gov. Accessed May 2020

Schmidt B, Schuphan I (2002) Metabolism of the environmental estrogen bisphenol A by plant cell suspension cultures. Chemosphere 49:5159. https://doi.org/10.1016/S0045-6535(02)00142-X

Shi Y, Sun Y, Xu H, Wu J (2019) Importance of organic matter to the retention and transport of bisphenol $\mathrm{A}$ and bisphenol $\mathrm{S}$ in saturated soils. Water Air Soil Pollut 230:43. https://doi.org/10.1007/s11270019-4096-y

Tarla DN, Erickson LE, Hettiarachchi GM, Amadi SI, Galkaduwa M, Davis LC, Nurzhanova A, Pidlisnyuk V (2020) Phytoremediation and bioremediation of pesticide-contaminated soil. Appl Sci 10: 1217. https://doi.org/10.3390/app 10041217

Taskin E, de Castro BC, Allegretta I, Terzano R, Rosa AH, Loffredo E (2019) Multianalytical characterization of biochar and hydrochar produced from waste biomasses for environmental and agricultural applications. Chemosphere 233:422-430. https://doi.org/10.1016/j. chemosphere.2019.05.204

Teixeira J, de Sousa A, Azenha M, Moreira JT, Fidalgo F, Silva AF, Faria JL, Silva AMT (2011) Solanum nigrum L. weed plants as a remediation tool for metalaxyl-polluted effluents and soils. Chemosphere 85:744-750. https://doi.org/10.1016/j.chemosphere.2011.06.049

Tong X, Li Y, Zhang F, Chen X, Zhao Y, Hu B, Zhang X (2019) Adsorption of $17-\beta$-estradiol onto humic-mineral complexes and effects of temperature, $\mathrm{pH}$, and bisphenol A on the adsorption process. Environ Pollut 254:112924. https://doi.org/10.1016/j.envpol. 2019.07.092

USEPA Office of Water Report (2003). Candidate contaminant list regulatory determination support document for metribuzin. https:// www.epa.gov/sites/production/files/2014-09/documents/support cc1_metribuzin_ccl_regdet.pdf. Accessed May 2020

Vandenberg LN, Maffini MV, Sonnenschein C, Rubin BS, Soto AM (2009) Bisphenol A and the great divide: a review of controversies in the field of endocrine disruption. Endocr Rev 30:75-95. https:// doi.org/10.1210/er.2008-0021

Wu S, Wu H (2019) Incorporating biochar into wastewater eco-treatment systems: popularity, reality, and complexity. Environ Sci Technol 53:3345-3346. https://doi.org/10.1021/acs.est.9b01101

Xu N, Zhang B, Tan G, Lia J, Wang H (2015) Influence of biochar on sorption, leaching and dissipation of bisphenol $\mathrm{A}$ and $17 \alpha$ ethynylestradiol in soil. Environ Sci Process Impacts 17:17221730. https://doi.org/10.1039/C5EM00190K

Ying GG, Williams B, Kookana R (2002) Environmental fate of alkylphenols and alkylphenol ethoxylates. A review. Environ Int 28:215-226. https://doi.org/10.1016/S0160-4120(02)00017-X

Zhang H, Wang JJ (2014). Loss on ignition method. In: Sikora FJ and Moore KP (eds) Soil test methods from the Southeastern United States. Southern extension and research activity information exchange group 6. University of Georgia, Athens, pp 155-157. http:// aesl.ces.uga.edu/sera6/PUB/MethodsManualFinalSERA6.asp. Accessed May 2020

Zhang X, Wang H, He L, Lu K, Sarmah A, Li J, Bolan NS, Pei J, Huang H (2013) Using biochar for remediation of soils contaminated with heavy metals and organic pollutants. Environ Sci Pollut Res 20: 8472-8483. https://doi.org/10.1007/s11356-013-1659-0

Zheng H, Zhang C, Liu B, Liu G, Zhao M, Xu G, Luo X, Li F, Xing B (2020) Biochar for water and soil remediation: production, characterization, and application. In: GB Jiang and XD Li (eds.) A new paradigm for environmental chemistry and Toxicology pp. 153-196. https://doi.org/10.1007/978-981-13-9447-8_11

Zhou JL (2006) Sorption and remobilization behavior of 4-tertoctylphenol in aquatic systems. Environ Sci Technol 40:22252234. https://doi.org/10.1021/es052002v

Publisher's note Springer Nature remains neutral with regard to jurisdictional claims in published maps and institutional affiliations. 